\title{
Loss of function of bHLH transcription factor Nrd1 in tomato induces an arabinogalactan protein-encoding gene and enhances resistance to Pseudomonas syringae pv. tomato
}

Ning Zhang ${ }^{1,2}$, Chloe Hecht ${ }^{1}$, Xuepeng Sun ${ }^{1}$, Zhangjun Fei ${ }^{1,2,3}$ and Gregory B. Martin ${ }^{1,2^{*}}$

${ }^{1}$ Boyce Thompson Institute for Plant Research, Ithaca, New York 14853, USA

${ }^{2}$ Plant Pathology and Plant-Microbe Biology Section, School of Integrative Plant Science, Cornell University, Ithaca, New York 14853, USA

${ }^{3}$ USDA-ARS Robert W. Holley Center for Agriculture and Health, Ithaca, NY 14853, USA

*Corresponding author: Gregory B. Martin (607-254-1208; gbm7@cornell.edu)

\section{ORCID IDs}

Ning Zhang: $\quad$ 0000-0003-2775-1755

Xuepeng Sun: $\quad 0000-0003-3471-8275$

Zhangjun Fei: $\quad$ 0000-0001-9684-1450

Gregory B. Martin: 0000-0003-0044-6830

Running title: Nrd1 negatively regulates tomato immunity

Key Words: tomato, Pseudomonas syringae pv. tomato, Nrd1, basic helix-loop-helix 


\begin{abstract}
Basic helix-loop-helix (bHLH) transcription factors constitute a superfamily in eukaryotes but their roles in plant immunity remain largely uncharacterized. We found that the transcript abundance in tomato leaves of one bHLH transcription factor-encoding gene, $\mathrm{Nrdl}$ (negative regulator of resistance to $\underline{\mathrm{DC}} 3000 \underline{1}$ ), was significantly increased after treatment with the immunity-inducing flgII-28 peptide. Plants carrying a loss-of-function mutation in $N r d 1(\Delta \mathrm{nrd} 1)$ showed enhanced resistance to Pseudomonas syringae pv. tomato (Pst) DC3000 although early pattern-triggered immunity responses such as generation of reactive oxygen species and activation of mitogen-activated protein kinases after treatment with flagellin-derived flg22 and flgII-28 peptides were unaltered compared to wild-type plants. An RNA-Seq analysis identified a gene, Agpl, whose expression is strongly suppressed in an Nrd1-dependent manner. Agpl encodes an arabinogalactan protein and overexpression of the Agpl gene in Nicotiana benthamiana led to $\sim 10$-fold less Pst growth compared to the control. These results suggest that the Nrd1 protein promotes tomato susceptibility to Pst by suppressing the defense gene Agpl. RNA-Seq also revealed that loss of Nrd1 function has no effect on the transcript abundance of immunity-associated genes including Bti9, Core, Fls2, Fls3 and Wakl upon Pst inoculation, suggesting that the enhanced immunity observed in the $\Delta \mathrm{nrd} 1$ mutants is due to the activation of key PRR signaling components as well as loss of Nrd1-regulated suppression of Agpl.
\end{abstract}




\section{Introduction}

Plants have evolved sophisticated surveillance mechanisms to rapidly recognize and respond to pathogen attacks (Lolle et al., 2020; Zhou and Zhang, 2020). The first layer of plant immunity, referred as pattern-triggered immunity (PTI), is triggered when plant cells detect microbeassociated molecular patterns (MAMPs) through transmembrane pattern recognition receptors (PRRs) (DeFalco and Zipfel, 2021). Successful pathogens deploy effectors into plant cells that interfere with PTI, leading to effector-triggered susceptibility (ETS) (Abramovitch et al., 2006). To defeat ETS, plants activate a more robust immune response, the effector-triggered immunity (ETI), where the nucleotide-binding leucine-rich repeat (NB-LRR or NLR) proteins directly or indirectly recognize a given effector, resulting in a hypersensitive cell death response (HR) and disease resistance (Jones and Dangl, 2006; Lolle et al., 2020). Although PRR-mediated PTI and NLR-mediated ETI involve different activation mechanisms and different early signaling components, recent evidence suggests that the two layers share some downstream components and both are needed to ensure robust immunity (Ngou et al., 2021; Yuan et al., 2021a; Yuan et al., 2021b)

The interaction of tomato (Solanum lycopersicum) with the bacterial pathogen Pseudomonas syringae pv. tomato (Pst) is a well-developed model system for understanding the molecular basis of plant immunity and bacterial pathogenesis (Martin, 2012; Roberts et al., 2019; Wu and Kamoun, 2019; Xin et al., 2018). When Pst enters the apoplastic space of the tomato leaves, two flagellin-derived MAMPs, flg22 and flgII-28, are recognized by the tomato PRRs Fls2 and Fls3, respectively (Hind et al., 2016; Roberts et al., 2020; Zhang et al., 2020). MAMP detection activates early PTI responses such as production of reactive oxygen species (ROS), activation of the mitogen-activated protein kinase (MAPK) cascades, and transcriptional reprogramming of a subset of defense genes (Jia and Martin, 1999; Li et al., 2016; Nguyen et al., 2010; Zipfel, 2014). The two Pst effector proteins, AvrPto and AvrPtoB, bind and interfere with the protein kinase domain of Fls2, Fls3 and the co-receptor Bak1 thus disrupting the host response to these MAMPs (Cheng et al., 2011; Hind et al., 2016; Xiang et al., 2008). The two effectors are also recognized by the host kinases Pto and Fen and trigger the hypersensitive response through the NLR protein Prf (Kim et al., 2002; Oh and Martin, 2011; Pedley and Martin, 2003). 
RNA-Seq analyses have been used to identify PTI- and ETI-specific genes in the tomato-Pst system by inoculating plants with Pst strains eliciting only the PTI or ETI response (Pombo et al., 2014; Rosli et al., 2013). A subset of FIRE (flagellin-induced, repressed by effectors) genes were identified and the cell wall-associated kinase, SlWak1, was demonstrated to play a critical role in the PTI signaling pathway (Rosli et al., 2013; Zhang et al., 2020). Similarly, a subset of ETI-specific genes whose expression was induced specifically during ETI were identified and one kinase, Epk1, was shown to play a role in the host response to three effector proteins (Pombo et al., 2014). These RNA-Seq data provide a powerful resource for identifying novel immunityassociated genes involved in the tomato-Pst interaction.

We have recently reported the generation of hundreds of CRISPR/Cas-mediated tomato lines carrying mutations in putative immunity-associated genes (Jacobs et al., 2017; Zhang et al., 2020; Zheng et al., 2019). The availability of these tomato mutant lines provides a robust resource for the research community to test the function of specific genes in plant immunity and other biological processes (Roberts et al., 2020; Zhang et al., 2020; Zheng et al., 2019). We initially screened homozygous mutant plants by inoculating them with various $P s t$ strains, including DC3000, to determine if they play a demonstrable role in PTI or ETI. Additional experimental methods including a ROS assay, MAPK activation assay, reporter gene assay, and HR assay were also applied to the mutant collection to identify new components of response pathways during the tomato-Pst interaction.

The basic helix-loop-helix (bHLH) proteins are a superfamily of transcription factors (TFs) that play an essential role in diverse biological processes in animals and plants (Heim et al., 2003; Li et al., 2006; Sun et al., 2015; Toledo-Ortiz et al., 2003; Wang et al., 2015a; Wang et al., 2015b). The bHLH family is defined by the bHLH signature domain, which consists of a N-terminal basic region functioning as a DNA-binding motif recognizing the E-box element (CANNTG), and a C-terminal HLH region acting as a dimerization domain to form homodimer or heterodimer required for transcription factor functions (Toledo-Ortiz et al., 2003). The bHLH TFs can transcriptionally activate or suppress target genes by specifically binding to their promoters (Hu et al., 2020; Hussain et al., 2021; Xu et al., 2014). In tomato, 160 bHLH proteinencoding genes were identified (Sun et al., 2015; Wang et al., 2015b), but only a few have been 
functionally characterized (Du et al., 2015; Kim and Mudgett, 2019; Ling et al., 2002; Schwartz et al., 2017) and even fewer have been reported to play a critical role in plant immunity (Kim and Mudgett, 2019; Schwartz et al., 2017).

The transcript abundance of one gene, encoding a bHLH transcription factor, referred to now as SlNrdl ( $\underline{S}$. lycoperscicum negative regulator of resistance to DC3000 1, hereafter Nrd1), was previously found to be increased in tomato leaves specifically upon treatment with flgII-28. Here, through loss-of-function analyses we found that, unexpectedly, Nrd1 appears to act as a negative regulator in tomato immunity to Pseudomonas syringae pv. tomato DC3000. Using the CRISPR-generated $\Delta$ nrd 1 mutant plants and RNA-Seq we identified a gene encoding an arabinogalactan protein (Agpl), whose expression was strongly suppressed by Nrd1. Overexpression of Agpl in Nicotiana benthamiana led to significantly less Pst growth, indicating it is a Nrd1-regulated defense gene against Pseudomonas syringae.

\section{Results}

\section{Identification of Nrd1 and generation of stable loss-of-function mutants in tomato}

Previous RNA-Seq analyses revealed that the transcript abundance of tomato $\mathrm{Nrdl}$ gene (Solyc03g114230) was significantly increased in leaves after treatment with $1 \mu \mathrm{M}$ flgII-28 (Rosli et al., 2013), suggesting it might play an important role in the tomato-Pst PTI response. To study the possible role of $\mathrm{Nrdl}$ in tomato immunity, we generated three $\mathrm{T} 0$ knockout mutant lines in tomato cultivar RG-PtoR using CRISPR/Cas9 with a guide RNA (5'-

GTAGTCCAGAAAAGCTAGAC-3'; Fig. 1A), which targets the first exon of the Nrd1 gene. Two Nrd1 independent homozygous mutants ( $\Delta$ nrd1-1 and $\Delta$ nrd1-2) were derived and used in this study. The $\Delta$ nrd1-1 mutant has a 2-bp deletion, resulting in a premature stop codon at the $27^{\text {th }}$ amino acid (aa) of the Nrd1 protein, whereas $\Delta$ nrd1-2 contains a 13 -bp deletion, causing a premature stop codon at the $18^{\text {th }}$ aa (Fig. 1A). No morphological defects were observed in either of the two Nrdl mutant plants when grown under greenhouse conditions (Fig. 1B).

$N r d l$ encodes a bHLH transcription factor containing a domain that binds the E-box motif (CANNTG) in the promoter sequence of target genes (Sun et al., 2015). To determine if Nrd1 has close homologs in tomato, Arabidopsis, or rice, we performed multiple BLAST (Basic Local 
Alignment Search Tool) searches of the NCBI databases using the Nrd1 protein sequence as the query sequence and obtained a limited number of protein hits. Phylogenetic analysis revealed that the Nrd1 protein has two relatively close paralogs in tomato, Solyc03g114233 and Solyc03g114237 (Fig. 1C and Supplemental Fig. 1A), with 60.3\% and 65.0\% similarity to the Nrd1 protein sequence, respectively. Nothing appears to be known about the biological functions of the two Nrd1 paralogs, and they are newly annotated genes in the latest version of tomato reference genome (SL4.0; https://solgenomics.net). However, our RNA-Seq data revealed very low transcript levels of Solyc03g114233 and Solyc03g114237 in leaves of both wild-type RGPtoR plants and $\Delta$ nrd 1 mutants, whereas $N r d 1$ showed a much higher transcript abundance after Pst inoculation (Supplemental Fig. 1B). These results suggested that Nrd1, but not the two close paralogs, might play a role in the plant response to Pst. No clear orthologs of Nrd1 occur in Arabidopsis or rice, with the most closely related proteins (AT1G10585, AT1G10586, and Os01g01870) having a very low sequence similarity $(28.3 \%, 29.3 \%$, and $38.3 \%$, respectively) to Nrd1.

\section{Mutations in $\mathbf{N r d l}$ cause enhanced resistance to Pst in tomato}

To test whether loss-of-function mutations in $\mathrm{Nrdl}$ affect the ETI response to Pst, we vacuuminfiltrated Pst DC3000 into the two $\Delta$ nrdl mutants, wild-type RG-PtoR (which expresses the Pto and Prf genes allowing recognition of effectors AvrPto/AvrPtoB; (Martin, 2012)) and RG-prf3 (which has a mutation in $\operatorname{Prf}$ that makes the Pto pathway nonfunctional) plants (Fig. 2A). We observed no significant difference in bacterial populations between the $\Delta$ nrd1 mutants and wildtype RG-PtoR two days after inoculation, whereas bacterial populations were 10-fold more in RG-prf3 compared to $\Delta \mathrm{nrd} 1$ and RG-PtoR plants. Similarly, the $\Delta \mathrm{nrd} 1$ mutants and RG-PtoR plants had no disease symptoms whereas RG-prf3 showed severe disease symptoms six days after inoculation. These data indicate that Nrd1 does not have a major role in the ETI pathway acting against Pst DC3000.

To test whether Nrd1 contributes to PTI acting against $P s t$, we vacuum-infiltrated the two $\Delta$ nrd1 mutants and RG-PtoR with DC3000_avrPto $\Delta a v r P t o B(D C 3000 \Delta \Delta)$ (Fig. 2B), which lacks the AvrPto and AvrPtoB effectors and therefore cannot activate ETI. Both mutant lines, $\Delta$ nrd1-1 and $\Delta$ nrd1-2, showed $\sim 10$-fold smaller populations of Pst compared to wild-type RG-PtoR two days 
after bacterial inoculation. In addition, the $\Delta$ nrd 1 mutants developed much less symptoms of bacterial speck disease on leaves compared to RG-PtoR five days after inoculation. Thus, Nrd1 appears to act as a negative regulator of PTI against Pst DC3000, which was unexpected given that $N r d 1$ transcripts increase in abundance upon treatment with flgII-28, a MAMP, and we suspected it might make a positive contribution to PTI. The enhanced resistance in the $\Delta \mathrm{nrd} 1$ mutants to DC3000 $\Delta a v r P t o \Delta a v r P t o B$ was not observed in experiments with four other Pst strains or with Xanthomonas campestris pv. vesicatoria (also known as X. euvesicatoria; Supplemental Table 1).

\section{Mutations of $\mathrm{Nrdl}$ do not affect MAMP-induced ROS production or MAPK activation} ROS production and MAPK activation are two early PTI-associated responses in bacterialinoculated plants. To investigate whether $\mathrm{Nrdl}$ contributes to these PTI responses, we performed ROS and MAPK activation assays using the two flagellin-derived peptides, flg22 and flgII-28

(Fig. 3). We observed no difference in either ROS production or MAPK activation in the $\triangle$ nrd11 and $\Delta$ nrd1-2 mutant lines compared to wild-type plants when treated with these peptides, indicating that role of Nrdl in PTI is downstream or independent of ROS and MAPK signaling pathways.

\section{RNA sequencing identifies putative $\mathrm{Nrd1}$-regulated defense and susceptibility genes}

Based on the enhanced resistance to Pst in the $\Delta$ nrd 1 mutants, we hypothesize that the increased abundance of the $\mathrm{Nrdl}$ transcripts after flgII-28 treatment leads to increased Nrd1 protein that acts to suppress a subset of defense-related (D) genes and/or induces a subset of susceptibility (S) genes, thus promoting the growth of Pst. If this were the case, then in the $\Delta$ nrd1 mutants, the Nrd1-regulated defense genes would be induced or no longer suppressed while the $\mathrm{S}$ genes would be suppressed, resulting in enhanced resistance to Pst infection. To identify possible Nrd1-regulated genes, we performed an RNA-Seq analysis using the two $\Delta$ nrd1 mutants and

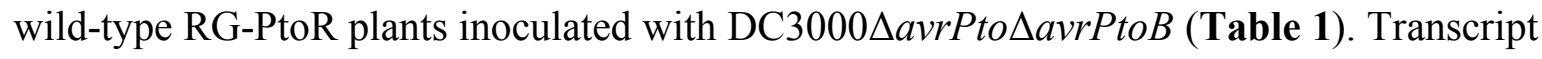
levels were quantified as fragments per kilobase of transcript per million mapped fragments (FPKM), and ranged from 0 to approximately 10,000 for the genes predicted in the tomato genome. A total of 51 genes were differentially expressed in both $\Delta \mathrm{nrd} 1-1$ and $\Delta \mathrm{nrd} 1-2$ mutants compared to wild-type plants (Supplemental Table 2). From these, we selected six putative 
defense-related genes (fold-change $\geq 2$ and adjusted $p<0.05$ ) and three putative susceptibility genes (fold-change $<0.5$ and adjusted $p<0.05$ ), based on two criteria: 1 ) the transcript abundance was $\geq 2$ FPKM in either $\Delta \mathrm{nrd} 1$ mutants or wild-type plants; and 2) the expression of putative $N r d 1$-regulated defense genes (up-regulated in $\Delta \mathrm{nrd} 1$ mutants) was suppressed after flgII-28 treatment in wild-type plants, while the putative susceptibility (S) genes (down-regulated in $\Delta$ nrd1 mutants) were induced by flgII-28 in wild-type plants, based on previous RNA-Seq data (Rosli et al., 2013) (Supplemental Table 2). Using the motif-searching database PlantPan2.0 (Chow et al., 2016), we found 1 to 5 copies of the E-box element (CANNTG) in the promoters of these nine candidate genes (Supplemental Fig. 2), indicating Nrd1 potentially binds to their promoters to either induce (S genes) or suppress (D genes) their expression.

\section{Overexpression of Agp1 in Nicotiana benthamiana significantly inhibits bacterial growth}

To test the possible functions of the Nrd1-regulated genes in defense or susceptibility, we performed an agromonas assay (Buscaill et al., 2021). In this assay, agroinfiltration is used first to overexpress the gene of interest in $N$. benthamiana leaves followed 2 days later by syringe-

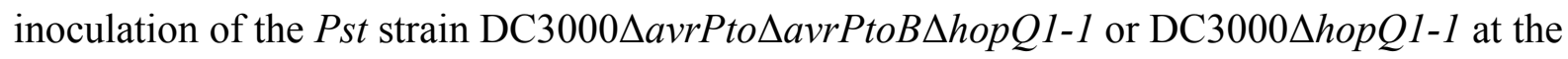
same agroinfiltrated spots (Fig. 4 and Supplemental Fig. 3). HopQ is recognized by NLR Roq in N. benthamiana and its deletion makes DC3000 virulent on this species (Schultink et al., 2017; Wei et al., 2007)). We hypothesized that overexpression of an important defense gene would inhibit Pst growth, while overexpression of an essential S gene would promote Pst growth. Among the nine candidate genes tested, overexpression in $N$. benthamiana leaves of the putative defense-related gene D6, Agpl (Solyc08g078020), encoding an arabinogalactan protein, led to 8 - to 10-fold less bacterial growth when inoculated with DC3000 4 avrPto $\Delta a v r P t o B \Delta h o p Q 1-1$ or DC3000 $h o p Q 1-1$, indicating Agp1 plays a critical role in tomato resistance to Pst. Expression of all proteins was confirmed by Western blot

\section{(Supplemental Fig. 3)}

Agp1 has a predicted signal peptide (SP) and a glycosylphosphatidylinositol (GPI) lipid anchor and, like other arabinogalactan proteins, it is likely associated with the outer leaflet of the plasma membrane (Silva et al., 2020). To investigate the potential function of the Agp1 SP and GPI anchor in immunity, we introduced amino acid substitutions into the SP sequence (SP-L12H and 
SP-T20K/A22H) or GPI-anchor sequence (GPI-S128K/S129K and GPI-F151K/F152K), or deleted the entire SP $(\Delta \mathrm{SP})$ or GPI-anchor sequence $(\Delta \mathrm{GPI})$ (Fig. 5). We then performed the agromonas assay to test whether the effect of these substitutions on Agp1-mediated immunity to Pst. All of the substitutions, except SP-L12H and GPI-S128K/S129K, impacted the ability of Agp1 to suppress Pst DC3000 growth compared to the wild-type Agp1 which, as expected, significantly inhibited bacterial growth in this assay (Fig. 5). Each of the variant proteins was expressed similar to wild-type Agp1, except for the one lacking the entire SP protein, probably due to protein degradation (Fig. 5). The mass of the Agp1 protein and its variants was more than twice than expected based solely on their amino acid sequences, likely due to glycosylation, as Agp1 contains 28 predicted glycosylated sites (Steentoft et al., 2013) (Supplemental Fig. 4). Overall, these results showed signal peptide sequence and GPI-anchor sequence are essential for Agp1-mediated resistance to Pst.

\section{Loss of Nrd1 function has no effect on the transcript abundance of multiple PTI-associated genes}

Multiple tomato immunity-associated genes including Bti9, Core, Fls2, Fls3 and Wak1 play important roles in PTI responses (Hind et al., 2016; Roberts et al., 2020; Rosli et al., 2013; Wang et al., 2016; Zeng et al., 2012; Zheng et al., 2019). We analyzed our RNA-Seq data to determine whether loss of Nrd1 function affects transcript abundance of these immunity-associated genes upon inoculation with the PTI-inducing strain DC3000_avrPto_avrPtoB (Supplemental Table 3). Interestingly, no significant difference of the transcript abundance of these genes was observed between the two $\Delta$ nrd1 mutant lines and the wild-type plants. It has been reported that Bti9, Core, Fls2, Fls3 and Wakl are greatly upregulated in wild-type RG-PtoR plants upon inoculation with DC3000 $a v r P t o \Delta a v r P t o B$ (Rosli et al., 2013), indicating that these genes were also induced in the $\Delta$ nrd1 mutants by this Pst strain regardless of the loss of Nrd1function. In all, the enhanced immunity observed in the $\Delta \mathrm{nrd} 1$ mutants is likely due to the activation of key components of PRR signaling ( Fls2/Fls3/Wakl, etc.) as well as loss of Nrd1-regulated suppression of the defense gene Agpl. 


\section{Discussion}

The $N r d 1$ gene was originally identified from a small subset of 44 genes whose transcript abundance in tomato leaves increased in response to flgII-28 but not in response to flg22 or csp22 (Rosli et al., 2013). This specificity was subsequently confirmed by RT-qPCR and Nrd1 is therefore useful as a reporter gene for the Fls3 pathway (Roberts et al., 2020). Because the gene is induced by flgII-28 we anticipated that a loss-of-function mutation in $\mathrm{Nrdl}$ might lead to loss of certain aspects of pattern-triggered immunity. However, unexpectedly, two independent $\Delta \mathrm{nrd} 1$ mutants showed enhanced resistance specifically to Pst DC3000, indicating the Nrd1 protein acts as a negative regulator of resistance to this Pst strain. An RNA-Seq analysis of the $\Delta \mathrm{nrd} 1$ mutants identified a small number of genes whose transcript abundance is either increased or decreased in an Nrd1-dependent manner and we hypothesized these genes might play a role in defense or susceptibility, respectively. Overexpression of one of the putative defense genes, Agp1, encoding an arabinogalactan protein, did in fact enhance resistance to DC3000, suggesting that it plays a role in the enhanced resistance of the $\Delta$ nrd1 mutants. Here we place Nrd1 in the context of previous reports of negative regulators of immunity, and we discuss the possible role of Agp1 in defense, propose a model for Fls3-specific transcriptional reprogramming, and consider the prospect that Nrd1/Agp1 might be used to identify a unique component of Pst DC3000 that is involved in the enhanced resistance observed in the $\Delta \mathrm{nrd} 1$ mutants.

Negative regulators of plant immunity can be viewed as susceptibility (S) genes since their expression allows enhanced growth of the pathogen and accordingly enhanced disease (van Schie and Takken, 2014). S genes have been classified into those that play a role in host recognition, suppression of host defenses, or in pathogen sustenance and they encode diverse proteins including transporters, protein kinases, membrane-associated proteins (e.g., Mlo), and enzymes (e.g., Dmr6) (Santillan Martinez et al., 2020; Thomazella et al., 2021; van Schie and Takken, 2014; Zheng et al., 2013). Of particular relevance here, several S genes encode transcription factors in the bHLH, bZIP, ERF, and WRKY families (Fan et al., 2014; Fang et al., 2021; Jin et al., 2011; Lu et al., 2020; Prior et al., 2021; Schwartz et al., 2017; Wang et al., 2015a). Similar to Nrd1, a few bHLH transcription factors have been found previously to act as negative regulators of disease resistance in plants. For instance, two tomato bHLH genes, SlbHLH3 and SlbHLH6, are up-regulated by the transcription activator-like effector (TALE) 
AvrHah1 in Xanthomonas gardneri and promote susceptibility of tomato to bacterial spot disease (Schwartz et al., 2017). bHLH TFs in other plant species, including the well-characterized HBI1 in Arabidopsis thaliana, negatively regulates a subset of genes involved in plant immunity and mediates a trade-off between growth and immunity in plants (Fan et al., 2014). In contrast to these bHLH negative regulators which are either induced by bacterial effectors (Schwartz et al., 2017) or suppressed by MAMPs or other bacterial components (Fan et al., 2014), the Nrdl gene is induced specifically by a flagellin-derived MAMP flgII-28 but acts in a way that promotes bacterial pathogenesis.

The tomato receptor Fls3 binds flgII-28 and works in concert with the co-receptor BAK1 (in tomato, Serk3A and/or Serk3B) to activate intracellular signaling (Hind et al., 2016). Our present and previous RNA-Seq analysis and the phenotype of the $\Delta$ nrd1 mutants together are consistent with a model in which Fls3 activates both resistance-enhancing and susceptibility-enhancing responses (Fig. 6). To resist Pst infection, Fls3 and other PRRs activate PTI responses leading to the rapid generation of ROS, activation of MAPKs and extensive changes in transcriptional programming that inhibit Pst growth. Fls3 also induces $\mathrm{Nrdl}$ gene expression and likely increases Nrd1 protein abundance which, we propose, suppresses a subset of defense genes and induces a subset of susceptibility genes promoting tomato susceptibility to Pst infection. In a loss-of-function mutation in $\mathrm{Nrdl}$ the subset of defense genes, including $\mathrm{Agpl}$, are no longer suppressed (or are induced) and S genes are not expressed, leading to enhanced Pst resistance. Additionally, in the $\Delta \mathrm{nrd} 1$ mutants, multiple well-characterized defense genes including Bti9, Core, Fls2, Fls3 and Wakl are still induced upon Pst inoculation (Supplemental Table 3), and ROS production and MAPK activation are not compromised (Fig. 3), suggesting that the observed increased resistance in the $\Delta \mathrm{nrd} 1$ mutants is due to the activation of key PRR signaling components as well as loss of Nrd1-regulated suppression of some defense genes such as Agpl and/or loss of Nrd1-regulated induction of certain S genes.

The discovery that overexpression of the tomato Agp1 gene significantly reduced DC3000 populations in leaves further reinforces the importance of the plant cell wall as the location for key immunity-associated activities (Bacete et al., 2018; Molina et al., 2021). Arabinogalactanproteins (AGPs) belong to a large family of cell wall hydroxyproline-rich glycoproteins that are 
involved in diverse biological processes including plant growth and development and plantmicrobe interactions (Gaspar et al., 2004; Seifert and Roberts, 2007). Classical AGPs contain an N-terminal hydrophobic secretion signal, a central domain rich in PAST (Pro, Ala, Ser, and Thr) residues, and a hydrophobic C-terminal sequence that directs the attachment of GPI anchor (Silva et al., 2020), whose presence or absence has been demonstrated to play a major impact on the host immune response to pathogen infection (Butikofer et al., 2001). GPI modification also allows the defense-associated protein NDR1 to attach on the outer surface of the plasma membrane, thus positively regulating disease resistance to multiple bacterial and fungal pathogens (Century et al., 1997; Century et al., 1995; Coppinger et al., 2004). In yeast, lesions in GPI-anchor production prevent certain proteins reaching the cell surface leading to cell wall defects and even death (Kinoshita et al., 1997). Consistent with this, we found removal of the GPI anchor from Agp1 caused a loss of $N$. benthamiana resistance to Pst DC3000, indicating the essential role of GPI anchor on Agp1 function in the tomato immune response, likely by disrupting the association of the Agp1 protein with the extracellular face of the plasma membrane. Additionally, Agp1 appeared to be heavily glycosylated, a common post-translational modification in AGPs that might regulate protein conformation, activity and stability in hostpathogen interactions (Lin et al., 2020).

The molecular mechanisms of AGPs in plant-microbe interactions remain largely unknown. It has been proposed that GPI-anchored proteins can be involved in signaling via phospholipase cleavage of the protein from the lipid anchor or via interactions with other plasma membrane or cell wall-associated proteins that are able to activate signaling pathways (Schultz et al., 1998; Schultz and Harrison, 2008; Yeats et al., 2018; Zhou, 2019). It is intriguing to speculate that GPI-anchored Agp1 might act in a complex with PRRs and modulate ligand recognition specificity (Yeats et al., 2018; Zhou, 2019) or that Agp1 interacts with the cell-wall associated kinase SlWak1 (Zhang et al., 2020) after release of Agp1 from the plasma membrane by cleavage of the GPI anchor; AGP epitopes have been reported to co-localize with Waks in tobacco protoplasts (Gens et al., 2000). Degradation products of AGPs might also function as damageassociated molecular patterns (DAMPs) eliciting a defense response (Villa-Rivera et al., 2021). In this regard, Arabidopsis WAK1 has been demonstrated to be a receptor of oligogalacturonides (OGs), an important component of some DAMPs (Brutus et al., 2010). The observation that 
AGPs localize in lipid rafts where many receptor proteins are clustered further supports the hypothesis that Agp1 might associate with certain defense-associated receptors (Ellis et al., 2010). Although these studies suggest possible molecular mechanisms of AGPs in plant-microbe interaction, more experiments are needed to understand how Agp1 enhances plant defense.

Loss-of-function mutations in S genes might offer a promising approach to enhancing broadspectrum disease resistance, as long as the mutation does not have pleiotropic detrimental effects. There are several examples of this strategy in the literature, although none yet involve a bHLH transcription factor (Hanika et al., 2021; Santillan Martinez et al., 2020; Seifert and Roberts, 2007; Sun et al., 2016; Thomazella et al., 2021; van Schie and Takken, 2014; Zheng et al., 2013). In contrast to such broad-spectrum activity, the enhanced resistance in the $\Delta$ nrd1 mutants appears specific to Pst DC3000 as the $\Delta$ nrd1 mutants were susceptible to four other strains of Pst and to the bacterial pathogen Xanthomonas (Supplemental Table 1). In light of this, although we saw no detrimental morphological or growth defects in the $\Delta$ nrd1 mutants they will likely not be generally useful for controlling bacterial speck disease. However, our results do raise the possibility that DC3000 expresses a unique component, lacking in other Pst strains, that is recognized by the $\Delta \mathrm{nrd} 1$ mutants. The future identification of such a Pst component might lead to the discovery of a novel host recognition mechanism.

\section{Materials and Methods}

\section{Generation of $\mathrm{Nrd1}$ tomato mutants using CRISPR/Cas9}

To generate the $\Delta$ nrdl mutants in the tomato cultivar Rio Grande (RG)-PtoR, which has the Pto and Prf genes, we designed a guide RNA (5'-GTAGTCCAGAAAAGCTAGAC-3') that targets the first exon of $\mathrm{Nrdl}$ using the software Geneious R11 (Kearse et al., 2012). The gRNA cassette was cloned into the p201N:Cas9 binary vector as described previously (Jacobs et al., 2017). Tomato transformation was performed at the Biotechnology Center at the Boyce Thompson Institute as described previously (Zhang et al., 2020). Mutations were confirmed by Sanger sequencing at the Biotechnology Resource Center (BRC) at Cornell University. 


\section{Phylogenetic analyses}

The Nrd1 protein sequence was used as a query sequence to search for related sequences in tomato, Arabidopsis, and rice using the NCBI BLAST (https://blast.ncbi.nlm.nih.gov/Blast.cgi). Amino acid alignments were performed by ClustalW (https://www.genome.jp/toolsbin/clustalw). Phylogenetic trees were constructed with MEGA-X (Kumar et al., 2018) using the maximum likelihood method and JTT matrix-based model (Jones et al., 1992). Bootstrap analysis with 1000 replicates was performed. Positions containing gaps and missing data were eliminated.

\section{Bacterial inoculation}

Four-week-old $\Delta \mathrm{nrd1}$ and wild-type plants were vacuum-infiltrated with various Pst DC3000 strains at different titers, including DC3000 $\Delta a v r P t o \Delta a v r P t o B(\mathrm{DC} 3000 \Delta \Delta)$ or DC3000 $\Delta$ avrPto $\Delta a v r P t o B \Delta f l i C(\mathrm{DC} 3000 \Delta \Delta \Delta)$ at $5 \times 10^{4} \mathrm{cfu} / \mathrm{mL}$ or DC3000 at $1 \times 10^{6} \mathrm{cfu} / \mathrm{mL}$. Bacterial populations were measured at $3 \mathrm{~h}$ (Day 0) and two days after inoculation (Day 2). Photographs of disease symptoms were taken five or six days after bacterial inoculation.

\section{ROS assay}

ROS production was measured as described previously (Clarke et al., 2013). In brief, leaf discs were collected and floated in water overnight. Water was then removed and replaced with a solution containing flg22 (QRLSTGSRINSAKDDAAGLQIA) or flgII-28 (ESTNILQRMRELAVQSRNDSNSSTDRDA) at the indicated concentrations, in combination with $34 \mu \mathrm{g} / \mathrm{mL}$ luminol (Sigma-Aldrich) and $20 \mu \mathrm{g} / \mathrm{mL}$ horseradish peroxidase. ROS production was measured using a Synergy 2 microplate reader (BioTek).

\section{MAPK phosphorylation assay}

MAPK phosphorylation assay was performed as described previously (Zhang et al., 2020). Six leaf discs of $\Delta \mathrm{nrdl}$ mutant and wild-type plants were floated in water overnight. The leaf discs were then incubated with flg22 or flgII-28 at desired concentrations, or water only for $10 \mathrm{~min}$, and immediately frozen in liquid nitrogen. Protein was extracted using buffer containing $50 \mathrm{mM}$ Tris- $\mathrm{HCl}$ (pH 7.5), 10\% glycerol, 2 mM EDTA, 1\% Triton X-100, 5 mM DTT, 1\% protease inhibitor cocktail (Sigma-Aldrich), 0.5\% Phosphatase inhibitor cocktail 2 (Sigma-Aldrich). 
MAPK phosphorylation was determined using an anti-phospho-p44/42 MAPK(Erk1/2) antibody (anti-pMAPK; Cell Signaling).

\section{Construct generation}

The coding region of each putative defense or susceptibility gene was amplified from tomato cDNA using Phusion Hot Start II DNA polymerase (ThermoFisher Scientific) and gene-specific primers (Supplemental Table 4), then cloned into pJLSmart (Mathieu et al., 2014) by Gibson assembly. The gene expression cassette in pJLSmart was then cloned into the destiny vector pGWB414 via recombination reactions using LR Clonase II (ThermoFisher Scientific). Vectors were confirmed by Sanger sequencing and then transformed into Agrobacterium strain 1D1249 for transient expression and agromonas assay in $N$. benthamiana.

Amino acid substitutions in the signal peptide and GPI-anchor sequences of the Agp1 protein were determined using SignalP-5.0 (Almagro Armenteros et al., 2019) and NetGPI-1.1(Gíslason et al., 2021). Amino acid substitutions were generated with the Q5 site-directed mutagenesis kit (NEB) with specific primers (Supplemental Table 4). The signal peptide sequence (retaining ATG) and the GPI sequence were deleted by PCR with specific primers using Phusion Hot Start II DNA polymerase (Supplemental Table 4). All mutated fragments were first cloned into pJLSmart by Gibson assembly and then pGWB414 by LR reaction.

\section{Agromonas assay}

The agromonas assays were performed as described (Buscaill et al., 2021). Briefly, Agrobacterium strains 1D1249 carrying a binary vector (pGWB414) expressing the gene of interest was syringe-infiltrated into leaves of four-week-old $N$. benthamiana plants. Two days later, the same agroinfiltrated spots were syringe-infiltrated with either DC3000 4 hopQ1-1 or DC3000 4 hopQ1-1 $\Delta$ avrPto $\Delta a v r P t o B$ at $5 \times 10^{4} \mathrm{cfu} / \mathrm{mL}$. Bacterial populations were measured by serial dilutions on LB medium supplemented with $10 \mu \mathrm{g} / \mathrm{ml}$ cetrimide, $10 \mu \mathrm{g} / \mathrm{ml}$ fucidin and 50 $\mu \mathrm{g} / \mathrm{ml}$ cephaloridine (CFC; Oxoid ${ }^{\mathrm{TM}}$ C-F-C Supplement) two days after Pst inoculation. 


\section{Immunoblotting}

Total protein was extracted from $N$. benthamiana leaves using $250 \mu$ l extraction buffer consisting of $62.5 \mathrm{mM}$ Tris- $\mathrm{HCl}$ (pH 6.8), 2\% SDS (v/v), 10\% glycerol and 5\% $\beta$-mercaptoethanol. A 12 $\mu \mathrm{L}$ soluble protein solution mixed with $4 \mathrm{X}$ Laemmli sample buffer were boiled at $95^{\circ} \mathrm{C}$ for $5 \mathrm{~min}$ before loaded for gel electrophoresis. Protein was loaded on 4\% - 20\% precast SDS-PAGE gel (Bio-Rad), blotted on PVDF membrane (Merck Millipore), inoculated with $\alpha$-HA primary antibody $(1: 7000 ; \mathrm{v} / \mathrm{v})$ and $\alpha$-rat-HRP secondary antibody (1:10000; v/v), and developed with Piece ECL plus substrate (Thermo Scientific) for $5 \mathrm{~min}$.

\section{RNA-Seq}

Five-week-old wild-type RG-PtoR and the two lines of $\Delta$ nrd1 mutants were vacuum infiltrated with a suspension of DC3000 $\Delta$ avrPto $\Delta a v r P t o B$ at $5 \times 10^{6} \mathrm{cfu} / \mathrm{mL}$. Four biological replicates were performed for each treatment. Tissue samples were collected at $6 \mathrm{~h}$ after infiltration. Total RNA was isolated with the RNeasy Plant Mini Kit (Qiagen) according to the manufacturer's instructions. RNA was treated with DNase by column-based purification (RNase-Free DNase Kit, Qiagen). RNA libraries were prepared and sequenced on an Illumina HiSeq 4000 system. Raw RNA-Seq reads were processed to remove adaptors and low-quality sequences using Trimmomatic (version 0.36) with default parameters (Bolger et al., 2014). The remaining cleaned reads were aligned to the ribosomal RNA database (Quast et al., 2013) using bowtie (version 1.1.2; (Langmead, 2010)) allowing up to three mismatches, and those aligned were discarded. The remaining cleaned reads were mapped to the tomato reference genome (SL4.0 and ITAG4.1) using HISAT2 (version 2.1.0; (Kim et al., 2019)) with default parameters. Based on the alignments, raw read counts for each gene were calculated using HTSeq-count (Anders et al., 2015) and normalized to fragments per kilobase of transcript per million mapped fragments (FPKM). Raw read counts were then fed to DESeq2 (Love et al., 2014) to identify differentially expressed genes (DEGs), with a cutoff of adjusted $P$ value $<0.05$ and fold change $>2$.

\section{Acknowledgments}

We thank Liam Cleary, Brian Bell, Jay Miller, and Joe Ettenberger for plant care, and Joyce Van Eck for tomato transformation. Funding was provided by National Science Foundation grant IOS-1546625 (GBM and ZF). 


\section{Author contributions}

GBM and NZ conceived and designed the experiments. NZ designed gRNAs, constructed vectors, performed genotyping and phenotyping experiments, and analyzed the data. $\mathrm{CH}$ performed ROS assays. ZF and XS analyzed RNA-Seq data. NZ and GBM interpreted the data and wrote the manuscript. All the authors read and approved the manuscript.

\section{Conflict of interest}

The authors declare that they have no conflict of interest.

\section{References}

Abramovitch, R.B., Anderson, J.C., and Martin, G.B. (2006). Bacterial elicitation and evasion of plant innate immunity. Nature Reviews Molecular Cell Biology 7:601-611.

Almagro Armenteros, J.J., Tsirigos, K.D., Sonderby, C.K., Petersen, T.N., Winther, O., Brunak, S., von Heijne, G., and Nielsen, H. (2019). SignalP 5.0 improves signal peptide predictions using deep neural networks. Nat Biotechnol 37:420-423.

Anders, S., Pyl, P.T., and Huber, W. (2015). HTSeq--a Python framework to work with highthroughput sequencing data. Bioinformatics 31:166-169.

Bacete, L., Melida, H., Miedes, E., and Molina, A. (2018). Plant cell wall-mediated immunity: cell wall changes trigger disease resistance responses. Plant J 93:614-636.

Bolger, A.M., Lohse, M., and Usadel, B. (2014). Trimmomatic: A flexible trimmer for Illumina sequence data. Bioinformatics 30:2114-2120.

Brutus, A., Sicilia, F., Macone, A., Cervone, F., and De Lorenzo, G. (2010). A domain swap approach reveals a role of the plant wall-associated kinase 1 (WAK1) as a receptor of oligogalacturonides. Proc Natl Acad Sci USA 107:9452-9457.

Buscaill, P., Sanguankiattichai, N., Lee, Y.J., Kourelis, J., Preston, G., and van der Hoorn, R.A.L. (2021). Agromonas: a rapid disease assay for Pseudomonas syringae growth in agroinfiltrated leaves. Plant J 105:831-840.

Butikofer, P., Malherbe, T., Boschung, M., and Roditi, I. (2001). GPI-anchored proteins: now you see'em, now you don't. The FASEB Journal 15.

Century, K.S., et al., and Staskawicz, B.J. (1997). NDR1, a pathogen-induced component required for Arabidopsis disease resistance. Science 278:1963-1965.

Century, K.S., Holub, E.B., and Staskawicz, B.J. (1995). NDR1, a locus of Arabidopsis thaliana that is required for disease resistance to both a bacterial and a fungal pathogen. Proc Natl Acad Sciences USA 92:6597-6601. 
Cheng, W., Munkvold, K.R., Gao, H., Mathieu, J., Schwizer, S., Wang, S., Yan, Y.B., Wang, J., Martin, G.B., and Chai, J. (2011). Structural analysis of Pseudomonas syringae AvrPtoB bound to host BAK1 reveals two similar kinase-interacting domains in a type III effector. Cell Host \& Microbe 10:616-626.

Chow, C.N., Zheng, H.Q., Wu, N.Y., Chien, C.H., Huang, H.D., Lee, T.Y., Chiang-Hsieh, Y.F., Hou, P.F., Yang, T.Y., and Chang, W.C. (2016). PlantPAN 2.0: an update of plant promoter analysis navigator for reconstructing transcriptional regulatory networks in plants. Nucleic Acids Res 44:D1154-1160.

Clarke, C.R., Chinchilla, D., Hind, S.R., Taguchi, F., Miki, R., Ichinose, Y., Martin, G.B., Leman, S., Felix, G., and Vinatzer, B.A. (2013). Allelic variation in two distinct Pseudomonas syringae flagellin epitopes modulates the strength of plant immune responses but not bacterial motility. New Phytol 200:847-860.

Coppinger, P., Repetti, P.P., Day, B., Dahlbeck, D., Mehlert, A., and Staskawicz, B.J. (2004). Overexpression of the plasma membrane-localized NDR1 protein results in enhanced bacterial disease resistance in Arabidopsis thaliana. Plant J 40:225-237.

DeFalco, T.A., and Zipfel, C. (2021). Molecular mechanisms of early plant pattern-triggered immune signaling. Mol Cell 81:3449-3467.

Du, J., Huang, Z., Wang, B., Sun, H., Chen, C., Ling, H.Q., and Wu, H. (2015). SlbHLH068 interacts with FER to regulate the iron-deficiency response in tomato. Ann Bot 116:2334.

Ellis, M., Egelund, J., Schultz, C.J., and Bacic, A. (2010). Arabinogalactan-proteins: key regulators at the cell surface? Plant Physiol 153:403-419.

Fan, M., Bai, M.Y., Kim, J.G., Wang, T., Oh, E., Chen, L., Park, C.H., Son, S.H., Kim, S.K., Mudgett, M.B., et al. (2014). The bHLH transcription factor HBI1 mediates the trade-off between growth and pathogen-associated molecular pattern-triggered immunity in Arabidopsis. Plant Cell 26:828-841.

Fang, X., Meng, X., Zhang, J., Xia, M., Cao, S., Tang, X., and Fan, T. (2021). AtWRKY1 negatively regulates the response of Arabidopsis thaliana to Pst. DC3000. Plant physiology and biochemistry : PPB / Societe francaise de physiologie vegetale 166:799806.

Gaspar, Y.M., Nam, J., Schultz, C.J., Lee, L.Y., Gilson, P.R., Gelvin, S.B., and Bacic, A. (2004). Characterization of the Arabidopsis lysine-rich arabinogalactan-protein AtAGP17 mutant (rat1) that results in a decreased efficiency of agrobacterium transformation. Plant Physiol 135:2162-2171.

Gens, J.S., Fujiki, M., and Pickard, B.G. (2000). Arabinogalactan protein and wall-associated kinase in a plasmalemmal reticulum with specialized vertices. Protoplasma 212:115-134. 
Gíslason, M.H., Nielsen, H., Almagro Armenteros, J.J., and Johansen, A.R. (2021). Prediction of GPI-anchored proteins with pointer neural networks. Current Research in Biotechnology $3: 6-13$.

Hanika, K., Schipper, D., Chinnappa, S., Oortwijn, M., Schouten, H.J., Thomma, B., and Bai, Y. (2021). Impairment of Tomato WAT1 Enhances Resistance to Vascular Wilt Fungi Despite Severe Growth Defects. Front Plant Sci 12:721674.

Heim, M.A., Jakoby, M., Werber, M., Martin, C., Weisshaar, B., and Bailey, P.C. (2003). The basic helix-loop-helix transcription factor family in plants: a genome-wide study of protein structure and functional diversity. Mol Biol Evol 20:735-747.

Hind, S.R., Strickler, S.R., Boyle, P.C., Dunham, D.M., Bao, Z., O'Doherty, I.M., Baccile, J.A., Hoki, J.S., Viox, E.G., Clarke, C.R., et al. (2016). Tomato receptor FLAGELLINSENSING 3 binds flgII-28 and activates the plant immune system. Nat Plants 2:16128.

Hu, D.G., Wang, N., Wang, D.H., Cheng, L., Wang, Y.X., Zhao, Y.W., Ding, J.Y., Gu, K.D., Xiao, X., and Hao, Y.J. (2020). A basic/helix-loop-helix transcription factor controls leaf shape by regulating auxin signaling in apple. New Phytol 228:1897-1913.

Hussain, A., Noman, A., Arif, M., Farooq, S., Khan, M.I., Cheng, P., Qari, S.H., Anwar, M., Hashem, M., Ashraf, M.F., et al. (2021). A basic helix-loop-helix transcription factor CabHLH113 positively regulate pepper immunity against Ralstonia solanacearum. Microb Pathog 156:104909.

Jacobs, T.B., Zhang, N., Patel, D., and Martin, G.B. (2017). Generation of a collection of mutant tomato lines using pooled CRISPR libraries. Plant Physiol 174:2023-2037.

Jia, Y., and Martin, G.B. (1999). Rapid transcript accumulation of pathogenesis-related genes during an incompatible interaction in bacterial speck disease-resistant tomato plants. Plant Mol Biol 40:455-465.

Jin, J., Hewezi, T., and Baum, T.J. (2011). The Arabidopsis bHLH25 and bHLH27 transcription factors contribute to susceptibility to the cyst nematode Heterodera schachtii. Plant $\mathrm{J}$ 65:319-328.

Jones, D.T., Taylor, W.R., and Thornton, J.M. (1992). The rapid generation of mutation data matrices from protein sequences. Comput Appl Biosci 8:275-282.

Jones, J.D., and Dangl, J.L. (2006). The plant immune system. Nature 444:323-329.

Kearse, M., Moir, R., Wilson, A., Stones-Havas, S., Cheung, M., Sturrock, S., Buxton, S., Cooper, A., Markowitz, S., Duran, C., et al. (2012). Geneious Basic: an integrated and extendable desktop software platform for the organization and analysis of sequence data. Bioinformatics 28:1647-1649. 
Kim, D., Paggi, J.M., Park, C., Bennett, C., and Salzberg, S.L. (2019). Graph-based genome alignment and genotyping with HISAT2 and HISAT-genotype. Nat Biotechnol 37:907915.

Kim, J.G., and Mudgett, M.B. (2019). Tomato bHLH132 Transcription Factor Controls Growth and Defense and Is Activated by Xanthomonas euvesicatoria Effector XopD During Pathogenesis. Mol Plant Microbe Interact 32:1614-1622.

Kim, Y.J., Lin, N.C., and Martin, G.B. (2002). Two distinct Pseudomonas effector proteins interact with the Pto kinase and activate plant immunity. Cell 109:589-598.

Kinoshita, T., Ohishi, K., and Takeda, J. (1997). GPI-anchor synthesis in mammalian cells: genes, their products, and a deficiency. J Biochem 122:251-257.

Kumar, S., Stecher, G., Li, M., Knyaz, C., and Tamura, K. (2018). MEGA X: Molecular Evolutionary Genetics Analysis across Computing Platforms. Mol Biol Evol 35:15471549.

Langmead, B. (2010). Aligning short sequencing reads with Bowtie. Curr Protoc Bioinformatics Chapter 11:Unit 1117.

Li, B., Meng, X., Shan, L., and He, P. (2016). Transcriptional regulation of pattern-triggered immunity in plants. Cell Host \& Microbe 19:641-650.

Li, X., Duan, X., Jiang, H., Sun, Y., Tang, Y., Yuan, Z., Guo, J., Liang, W., Chen, L., Yin, J., et al. (2006). Genome-wide analysis of basic/helix-loop-helix transcription factor family in rice and Arabidopsis. Plant Physiol 141:1167-1184.

Lin, B., Qing, X., Liao, J., and Zhuo, K. (2020). Role of Protein Glycosylation in Host-Pathogen Interaction. Cells 9.

Ling, H.Q., Bauer, P., Bereczky, Z., Keller, B., and Ganal, M. (2002). The tomato fer gene encoding a bHLH protein controls iron-uptake responses in roots. Proc Natl Acad Sci U S A 99:13938-13943.

Lolle, S., Stevens, D., and Coaker, G. (2020). Plant NLR-triggered immunity: from receptor activation to downstream signaling. Curr Opin Immunol 62:99-105.

Love, M.I., Huber, W., and Anders, S. (2014). Moderated estimation of fold change and dispersion for RNA-seq data with DESeq2. Genome Biol 15:550.

Lu, W., Deng, F., Jia, J., Chen, X., Li, J., Wen, Q., Li, T., Meng, Y., and Shan, W. (2020). The Arabidopsis thaliana gene AtERF019 negatively regulates plant resistance to Phytophthora parasitica by suppressing PAMP-triggered immunity. Mol Plant Pathol 21:1179-1193. 
Martin, G.B. (2012). Suppression and activation of the plant immune system by Pseudomonas syringae effectors AvrPto and AvrPtoB. In: Effectors in Plant-Microbe Interactions-Martin, F., and Kamoun, S., eds. Ames, IA: Wiley-Blackwell. 123-154.

Mathieu, J., Schwizer, S., and Martin, G.B. (2014). Pto kinase binds two domains of AvrPtoB and its proximity to the effector E3 ligase determines if it evades degradation and activates plant immunity. PLoS Pathog 10:e1004227.

Molina, A., Miedes, E., Bacete, L., Rodriguez, T., Melida, H., Denance, N., Sanchez-Vallet, A., Riviere, M.P., Lopez, G., Freydier, A., et al. (2021). Arabidopsis cell wall composition determines disease resistance specificity and fitness. Proc Natl Acad Sci U S A 118.

Ngou, B.P.M., Ahn, H.K., Ding, P., and Jones, J.D.G. (2021). Mutual potentiation of plant immunity by cell-surface and intracellular receptors. Nature 592:110-115.

Nguyen, H.P., Chakravarthy, S., Velásquez, A.C., McLane, H.S., Zeng, L., Park, D.-W., Collmer, A., and Martin, G.B. (2010). Methods to study PAMP-triggered immunity using tomato and Nicotiana benthamiana. Mol Plant-Microbe Interact 23:991-999.

Oh, C.-S., and Martin, G.B. (2011). Effector-triggered immunity mediated by the Pto kinase. Trends in Plant Science 16:132-140.

Pedley, K.F., and Martin, G.B. (2003). Molecular basis of Pto-mediated resistance to bacterial speck disease in tomato. Ann Rev Phytopathol 41:215-243.

Pombo, M.A., Zheng, Y., Fernandez-Pozo, N., Dunham, D.M., Fei, Z., and Martin, G.B. (2014). Transcriptomic analysis reveals tomato genes whose expression is induced specifically during effector-triggered immunity and identifies the Epk1 protein kinase which is required for the host response to three bacterial effector proteins. Genome Biol 15:492.

Prior, M.J., Selvanayagam, J., Kim, J.G., Tomar, M., Jonikas, M., Mudgett, M.B., Smeekens, S., Hanson, J., and Frommer, W.B. (2021). Arabidopsis bZIP11 Is a Susceptibility Factor During Pseudomonas syringae Infection. Mol Plant Microbe Interact 34:439-447.

Quast, C., Pruesse, E., Yilmaz, P., Gerken, J., Schweer, T., Yarza, P., Peplies, J., and Glockner, F.O. (2013). The SILVA ribosomal RNA gene database project: improved data processing and web-based tools. Nucleic Acids Res 41:D590-596.

Roberts, R., Liu, A.E., Wan, L., Geiger, A.M., Hind, S.R., Rosli, H.G., and Martin, G.B. (2020). Molecular characterization of differences between the tomato immune receptors Flagellin Sensing 3 and Flagellin Sensing 2. Plant Physiol 183:1825-1837.

Roberts, R., Mainiero, S., Powell, A.F., Liu, A.E., Shi, K., Hind, S.R., Strickler, S.R., Collmer, A., and Martin, G.B. (2019). Natural variation for unusual host responses and flagellinmediated immunity against Pseudomonas syringae in genetically diverse tomato accessions. New Phytol 223:447-461. 
Rosli, H.G., Zheng, Y., Pombo, M.A., Zhong, S., Bombarely, A., Fei, Z., Collmer, A., and Martin, G.B. (2013). Transcriptomics-based screen for genes induced by flagellin and repressed by pathogen effectors identifies a cell wall-associated kinase involved in plant immunity. Genome Biol 14:R139.

Santillan Martinez, M.I., Bracuto, V., Koseoglou, E., Appiano, M., Jacobsen, E., Visser, R.G.F., Wolters, A.A., and Bai, Y. (2020). CRISPR/Cas9-targeted mutagenesis of the tomato susceptibility gene PMR4 for resistance against powdery mildew. BMC Plant Biol 20:284.

Schultink, A., Qi, T., Lee, A., Steinbrenner, A.D., and Staskawicz, B. (2017). Roq1 mediates recognition of the Xanthomonas and Pseudomonas effector proteins XopQ and HopQ1. Plant J 92:787-795.

Schultz, C.J., Gilson, P., Oxley, D., Youl, J.J., and Bacic, A. (1998). GPI-anchors on arabinogalactanproteins: implications for signalling in plants. Trends in Plant Science 3.

Schultz, C.J., and Harrison, M.J. (2008). Novel plant and fungal AGP-like proteins in the Medicago truncatula-Glomus intraradices arbuscular mycorrhizal symbiosis. Mycorrhiza 18:403-412.

Schwartz, A.R., Morbitzer, R., Lahaye, T., and Staskawicz, B.J. (2017). TALE-induced bHLH transcription factors that activate a pectate lyase contribute to water soaking in bacterial spot of tomato. Proc Natl Acad Sci U S A 114:E897-E903.

Seifert, G.J., and Roberts, K. (2007). The biology of arabinogalactan proteins. Annu Rev Plant Biol 58:137-161.

Silva, J., Ferraz, R., Dupree, P., Showalter, A.M., and Coimbra, S. (2020). Three Decades of Advances in Arabinogalactan-Protein Biosynthesis. Front Plant Sci 11:610377.

Steentoft, C., Vakhrushev, S.Y., Joshi, H.J., Kong, Y., Vester-Christensen, M.B., Schjoldager, K.T., Lavrsen, K., Dabelsteen, S., Pedersen, N.B., Marcos-Silva, L., et al. (2013). Precision mapping of the human O-GalNAc glycoproteome through SimpleCell technology. EMBO J 32:1478-1488.

Sun, H., Fan, H.J., and Ling, H.Q. (2015). Genome-wide identification and characterization of the bHLH gene family in tomato. BMC Genomics 16:9.

Sun, K., Wolters, A.M., Vossen, J.H., Rouwet, M.E., Loonen, A.E., Jacobsen, E., Visser, R.G., and Bai, Y. (2016). Silencing of six susceptibility genes results in potato late blight resistance. Transgenic Res 25:731-742.

Thomazella, D.P.T., Seong, K., Mackelprang, R., Dahlbeck, D., Geng, Y., Gill, U.S., Qi, T., Pham, J., Giuseppe, P., Lee, C.Y., et al. (2021). Loss of function of a DMR6 ortholog in tomato confers broad-spectrum disease resistance. Proc Natl Acad Sci U S A 118. 
Toledo-Ortiz, G., Huq, E., and Quail, P.H. (2003). The Arabidopsis basic/helix-loop-helix transcription factor family. Plant Cell 15:1749-1770.

van Schie, C.C., and Takken, F.L. (2014). Susceptibility genes 101: how to be a good host. Annu Rev Phytopathol 52:551-581.

Villa-Rivera, M.G., Cano-Camacho, H., Lopez-Romero, E., and Zavala-Paramo, M.G. (2021). The Role of Arabinogalactan Type II Degradation in Plant-Microbe Interactions. Frontiers in microbiology 12:730543.

Wang, F., Lin, R., Feng, J., Qiu, D., Chen, W., and Xu, S. (2015a). Wheat bHLH transcription factor gene, TabHLH060, enhances susceptibility of transgenic Arabidopsis thaliana to Pseudomonas syringae. Physiological and Molecular Plant Pathology 90:123-130.

Wang, J., Hu, Z., Zhao, T., Yang, Y., Chen, T., Yang, M., Yu, W., and Zhang, B. (2015b). Genome-wide analysis of bHLH transcription factor and involvement in the infection by yellow leaf curl virus in tomato (Solanum lycopersicum). BMC Genomics 16:39.

Wang, L., Albert, M., Einig, E., Furst, U., Krust, D., and Felix, G. (2016). The patternrecognition receptor CORE of Solanaceae detects bacterial cold-shock protein. Nat Plants 2:16185.

Wei, C.F., Kvitko, B.H., Shimizu, R., Crabill, E., Alfano, J.R., Lin, N.C., Martin, G.B., Huang, H.C., and Collmer, A. (2007). A Pseudomonas syringae pv. tomato DC3000 mutant lacking the type III effector HopQ1-1 is able to cause disease in the model plant Nicotiana benthamiana. Plant J 51:32-46.

Wu, C.-H., and Kamoun, S. (2019). Tomato Prf requires NLR helpers NRC2 and NRC3 to confer resistance against the bacterial speck pathogen Pseudomonas syringae pv. tomato. bioRxiv https://doi.org/10.1101/595744

Xiang, T., Zong, N., Zou, Y., Wu, Y., Zhang, J., Xing, W., Li, Y., Tang, X., Zhu, L., Chai, J., et al. (2008). Pseudomonas syringae effector AvrPto blocks innate immunity by targeting receptor kinases. Curr Biol 18:74-80.

Xin, X.F., Kvitko, B., and He, S.Y. (2018). Pseudomonas syringae: what it takes to be a pathogen. Nat Rev Microbiol 16:316-328.

Xu, F., Kapos, P., Cheng, Y.T., Li, M., Zhang, Y., and Li, X. (2014). NLR-associating transcription factor bHLH84 and its paralogs function redundantly in plant immunity. PLoS Pathog 10:e1004312.

Yeats, T.H., Bacic, A., and Johnson, K.L. (2018). Plant glycosylphosphatidylinositol anchored proteins at the plasma membrane-cell wall nexus. J Integr Plant Biol 60:649-669.

Yuan, M., Jiang, Z., Bi, G., Nomura, K., Liu, M., Wang, Y., Cai, B., Zhou, J.M., He, S.Y., and Xin, X.F. (2021a). Pattern-recognition receptors are required for NLR-mediated plant immunity. Nature 592:105-109. 
Yuan, M., Ngou, B.P.M., Ding, P., and Xin, X.F. (2021b). PTI-ETI crosstalk: an integrative view of plant immunity. Curr Opin Plant Biol 62:102030.

Zeng, L., Velasquez, A.C., Munkvold, K.R., Zhang, J., and Martin, G.B. (2012). A tomato LysM receptor-like kinase promotes immunity and its kinase activity is inhibited by AvrPtoB. Plant Journal 69:92-103.

Zhang, N., Pombo, M.A., Rosli, H.G., and Martin, G.B. (2020). Tomato wall-associated kinase S1Wak1 acts in an Fls2- and Fls3-dependent manner to promote apoplastic immune responses to Pseudomonas syringae. Plant Physiol 183:1869-1882.

Zhang, N., Roberts, H.M., Van Eck, J., and Martin, G.B. (2020). Generation and molecular characterization of CRISPR/Cas9-induced mutations in 63 immunity-associated genes in tomato reveals specificity and a range of gene modifications. Front. Plant Sci. 11:1-13.

Zheng, Y., Zhang, N., Martin, G.B., and Fei, Z. (2019). Plant Genome Editing Database (PGED): A call for submission of information about genome-edited plant mutants. Mol Plant 12:127-129.

Zheng, Z., Nonomura, T., Appiano, M., Pavan, S., Matsuda, Y., Toyoda, H., Wolters, A.M., Visser, R.G., and Bai, Y. (2013). Loss of function in Mlo orthologs reduces susceptibility of pepper and tomato to powdery mildew disease caused by Leveillula taurica. PLoS One 8:e70723.

Zhou, J.M., and Zhang, Y. (2020). Plant Immunity: Danger Perception and Signaling. Cell 181:978-989.

Zhou, K. (2019). Glycosylphosphatidylinositol-Anchored Proteins in Arabidopsis and One of Their Common Roles in Signaling Transduction. Front Plant Sci 10:1022.

Zipfel, C. (2014). Plant pattern-recognition receptors. Trends in immunology 35:345-351. 
A

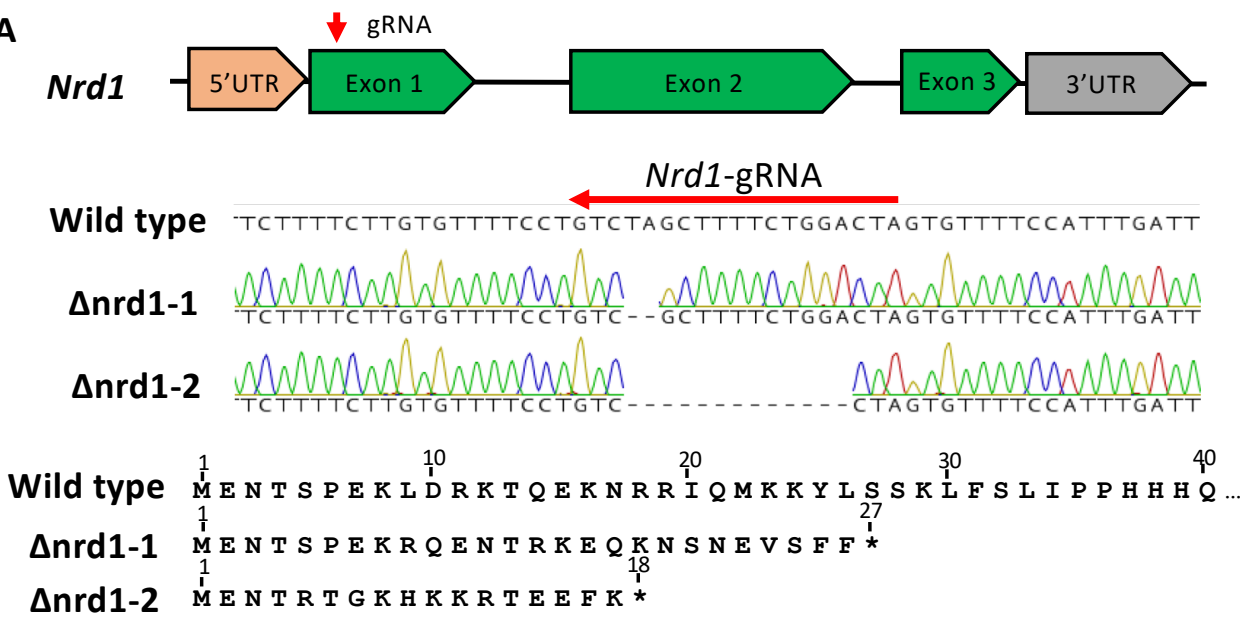

B

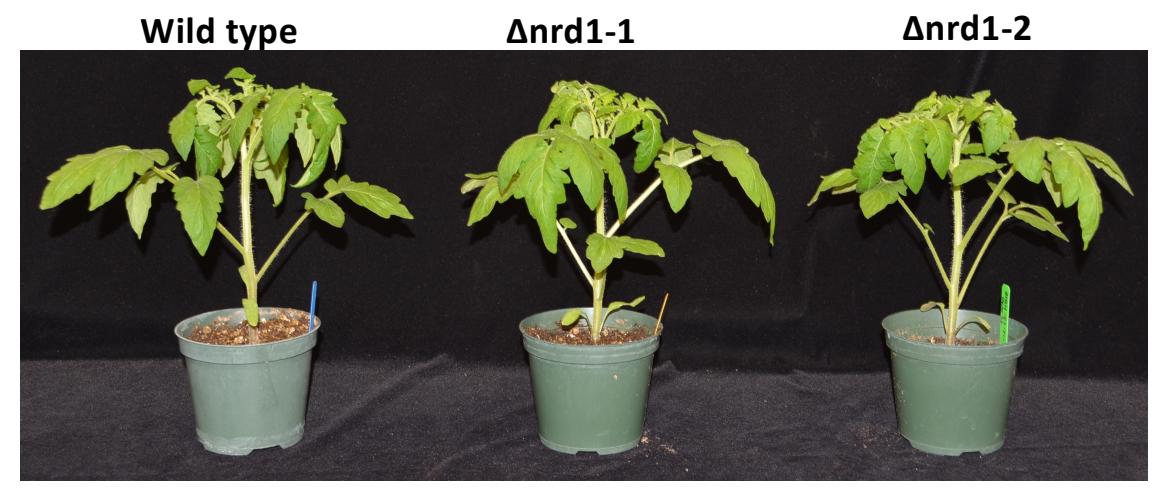

C

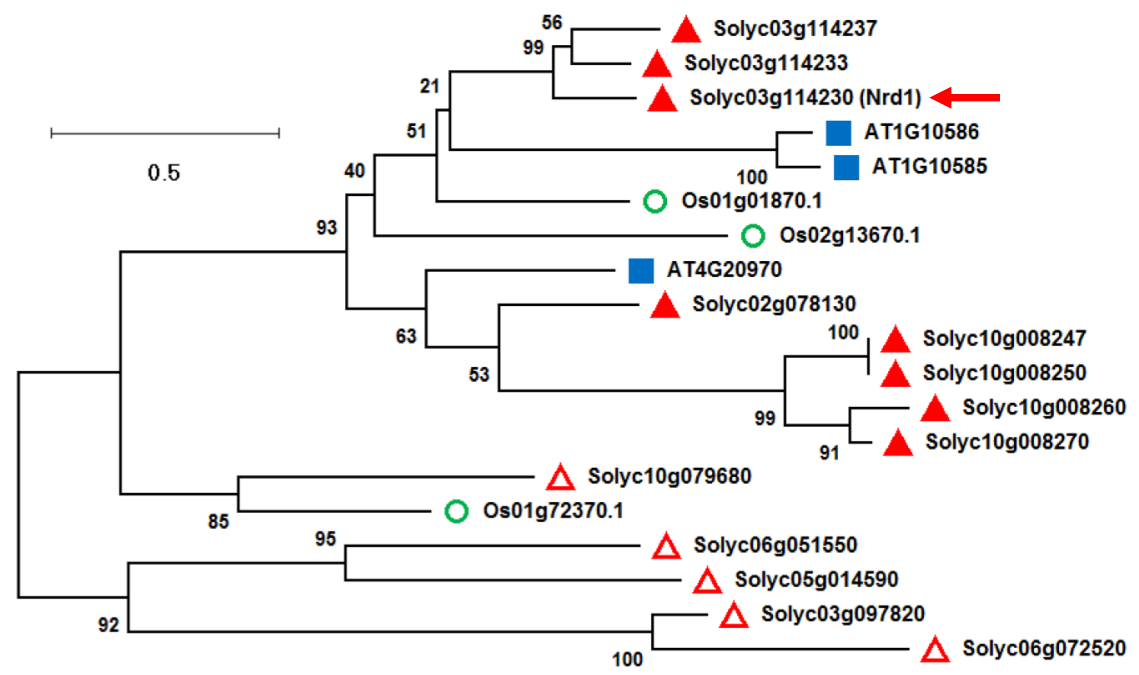

Figure 1. Generation of tomato $\Delta \mathrm{nrd1}$ mutants by CRISPR/Cas9. A, Schematics showing the guide-RNA (gRNA) target site and the missense mutations present in two independent $\Delta n r d 1$ lines. The $\Delta n r d 1-1$ line has a 2-bp deletion and the $\Delta$ nrd1-2 line has a 13-bp deletion. Wild type is RG-PtoR. Mutations in the lines introduce a premature stop codon at the $27^{\text {th }}$ or $18^{\text {th }}$ amino acid of the Nrd1 protein, respectively. B, Photographs of fourweek-old wild-type RG-PtoR and the two $\Delta \mathrm{nrd1}$ mutant lines grown in the greenhouse. C, Phylogenetic tree of Nrd1 and related proteins. Amino acid sequences of $\mathrm{Nrd} 1$ and related proteins in Arabidopsis, rice and tomato were used to generate a maximum likelihood tree. The tree is drawn to scale, with branch lengths measured in the number of substitutions per site. Numbers on branches indicate bootstrap support of the nodes (\%). The red arrow indicates the Nrd1 protein. Proteins identified by BLAST: closed red triangle (from tomato); blue box (from Arabidopsis); open circle (from rice). Open red triangles indicate tomato bHLH proteins that have been characterized previously (Du et al., 2015; Kim and Mudgett, 2019; Ling et al., 2002; Schwartz et al., 2017). 

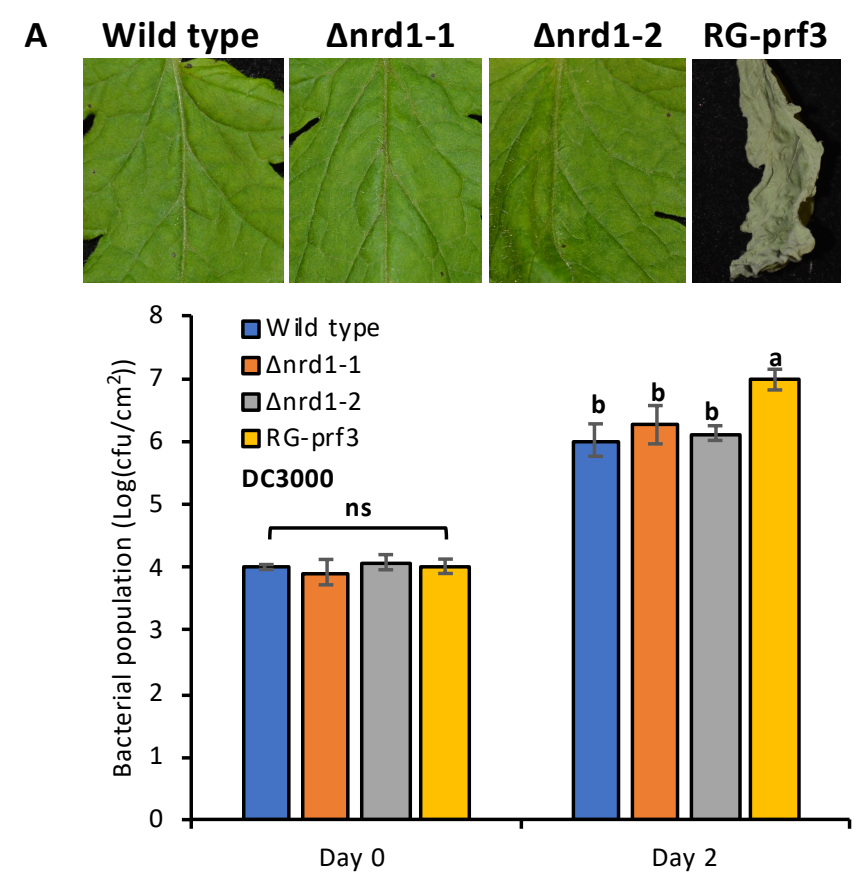

B
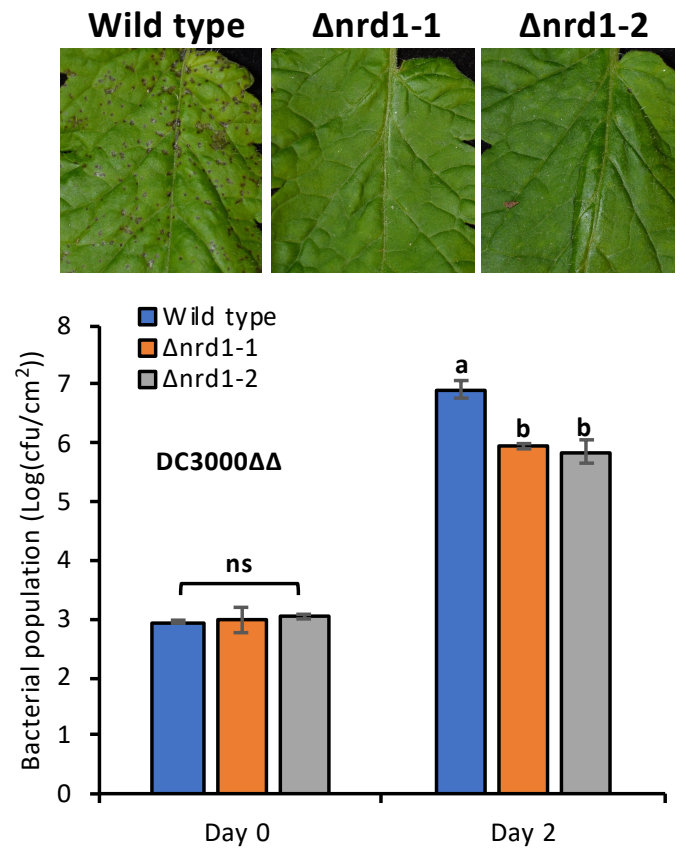

Figure 2. Investigation of ETI- and PTI-mediated immunity in the $\Delta \mathrm{nrd} \mathbf{1}$ mutants. Four-weekold $\Delta$ nrd1 plants, RG-PtoR (wild type), and RG-prf3 (a Prf mutant) plants were vacuum-

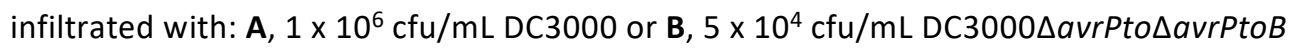
$(\mathrm{DC} 3000 \Delta \Delta)$. Photographs of disease symptoms were taken at 6 days (A) or 5 days (B) after inoculation. Bacterial populations were measured at 3 hours (Day 0 ) and two days (Day 2 ) after infiltration. Bars show means \pm standard deviation (SD). Different letters indicate significant differences based on a one-way ANOVA followed by Student's $t$ test $(p<0.05)$. ns, no significant difference. Three or four plants for each genotype were tested per experiment. The experiment was performed three times with similar results. 
A

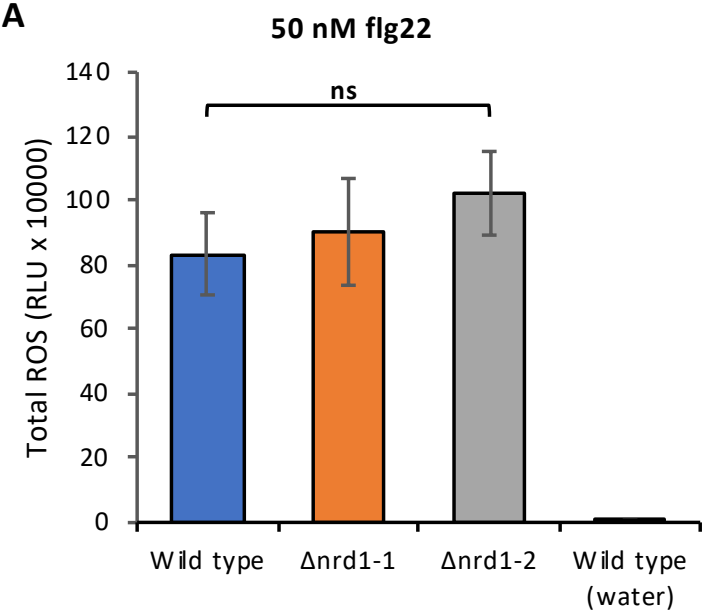

C

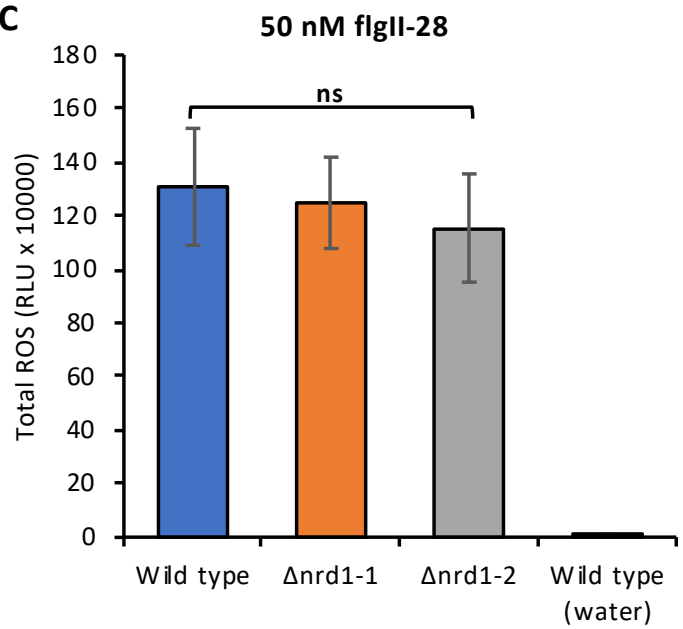

B

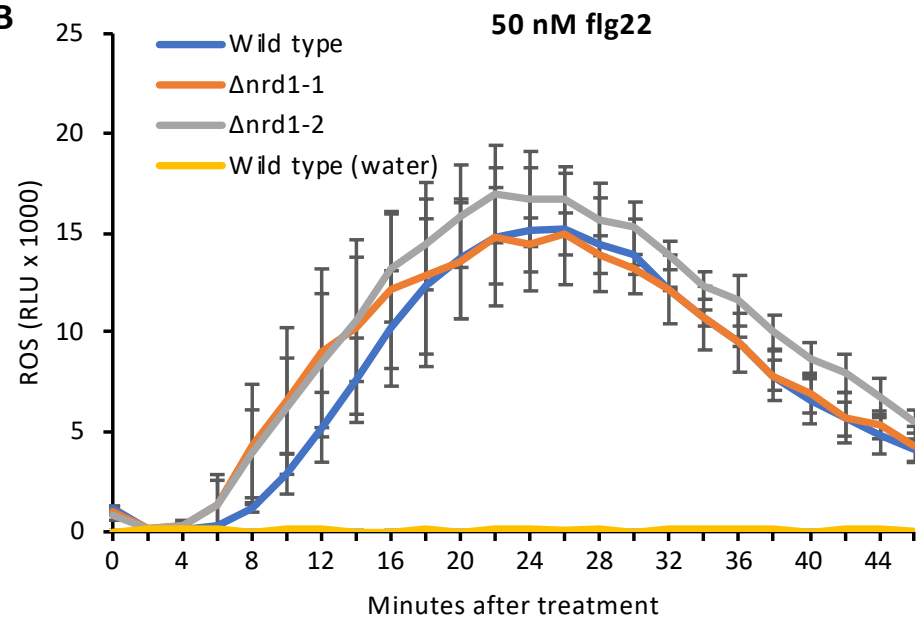

D

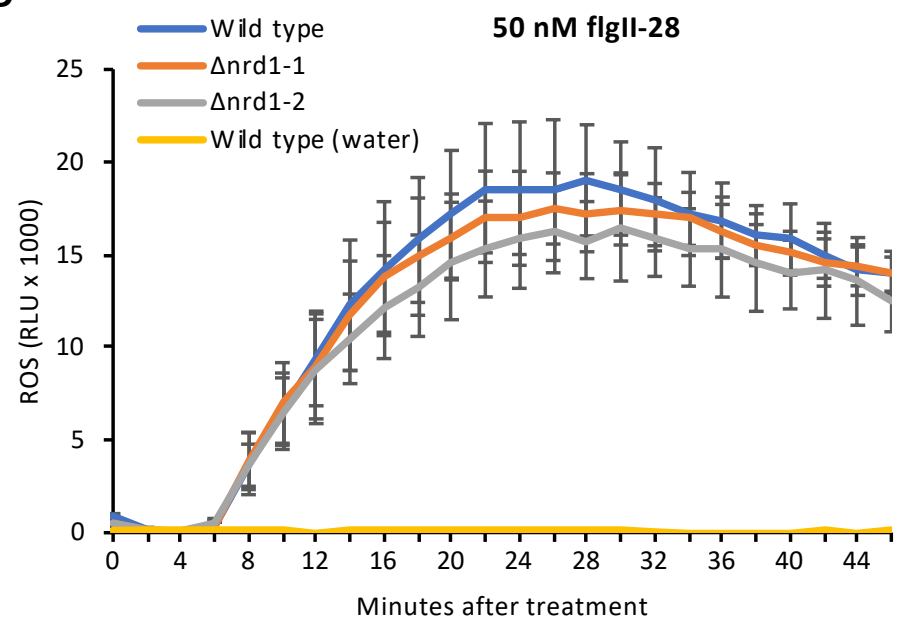

E

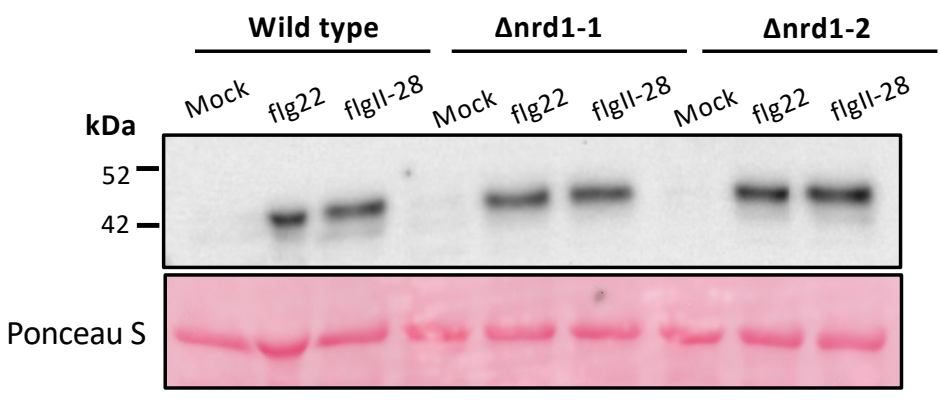

Figure 3. Investigation of MAMP-induced ROS production and MAPK activation in the $\triangle$ nrd1 mutants. A-D, Leaf discs from $\Delta \mathrm{nrd1}$ or RG-PtoR wild-type plants were treated with $50 \mathrm{nM}$ flg22 (A-B), $50 \mathrm{nM}$ flgll-28 (C-D), or water only. Relative light units (RLU) were measured over 45 minutes. One-way ANOVA followed by Student's $t$ test $(p<0.05)$ was performed for total $\operatorname{ROS}(\mathbf{A}, \mathbf{C})$ or at $24 \mathrm{~min}$ (peak readout) and $45 \mathrm{~min}$ after treatment with flg22 or flgll-28 (B, D). Bars represent means \pm SD. No significant difference was observed between $\Delta \mathrm{nrd1}$ and wild-type plants in either treatment. E, Leaf discs from wild-type RG-PtoR plants and $\Delta \mathrm{nrd} 1$ mutants were treated with $10 \mathrm{nM}$ flg22, $25 \mathrm{nM}$ flgll-28, or water (mock) for 10 min. Proteins were extracted from a pool of discs from plants of the three genotypes and subjected to immunoblotting using an anti-pMAPK antibody that detects phosphorylated MAPKs. Ponceau staining shows equal loading of proteins. 
Table 1. Nrd1-regulated putative defense-related genes and susceptibility genes identified by RNA-Seq. A, Summary of genes with increased or decreased transcript abundance in the $\Delta \mathrm{nrd} 1$ lines compared to wild type (RG-PtoR) 6 hours after inoculation with $5 \times 10^{6} \mathrm{cfu} / \mathrm{mL} \mathrm{DC3000 \Delta avrPto \Delta avrPtoB}$ (DC3000 $\Delta \Delta$ ). A $\geq 2$-fold difference and adjusted $p<0.05$ were used as cut-offs. B, Selected putative defense-related genes and susceptibility genes. ${ }^{*}$ Fold change of gene expression in $\Delta$ nrd1 lines compared to that in wild-type plants.

A

\begin{tabular}{cccc}
\hline Comparison & $\begin{array}{c}\text { Total \# of differentially } \\
\text { expressed genes }\end{array}$ & $\begin{array}{c}\text { \# of up- } \\
\text { regulated genes }\end{array}$ & $\begin{array}{c}\text { \# of down- } \\
\text { regulated genes }\end{array}$ \\
\hline$\Delta$ nrd1-1/wild type & 463 & 211 & 252 \\
$\Delta$ nrd1-2/wild type & 144 & 93 & 51 \\
Common & 51 & 43 & 8 \\
\hline
\end{tabular}

B

\begin{tabular}{|c|c|c|c|c|c|c|c|}
\hline & & Gene ID & Description & $\begin{array}{c}\Delta \text { nrd1-1/wild } \\
\text { type* }\end{array}$ & $\begin{array}{c}\text { Adjusted } \\
P\end{array}$ & $\begin{array}{c}\text { unrd1-2/wild } \\
\text { type* }\end{array}$ & $\begin{array}{c}\text { Adjusted } \\
P\end{array}$ \\
\hline \multirow{6}{*}{$\begin{array}{c}\text { Putative } \\
\text { defense-related } \\
\text { gene (up-regulated } \\
\text { in nrd1 mutants) }\end{array}$} & D1 & Solyc05g024190 & Chlorophyll synthase, chloroplastic & 2.857 & 0.001313 & 3.846 & 0.00792 \\
\hline & D2 & Solyc07g061790 & Heme-binding protein 2-like & 4.348 & $2.45 \mathrm{E}-05$ & 6.667 & $2.66 \mathrm{E}-08$ \\
\hline & D3 & Solyc02g077330 & GDSL esterase/lipase & 2.778 & 0.014041 & 3.571 & 0.01104 \\
\hline & D4 & Solyc12g009650 & SI proline-rich protein & 2.222 & $6.79 \mathrm{E}-13$ & 2.326 & 2.97E-05 \\
\hline & D5 & Solyc11g019910 & $\begin{array}{l}\text { Plant invertase/pectin } \\
\text { methylesterase inhibitor } \\
\text { superfamily protein }\end{array}$ & 2.128 & 0.00512 & 2.632 & $5.81 \mathrm{E}-05$ \\
\hline & D6 & Solyc08g078020 & Arabinogalactan & 3.125 & $3.81 \mathrm{E}-11$ & 3.704 & $3.40 \mathrm{E}-09$ \\
\hline $\begin{array}{c}\text { Putative } \\
\text { susceptibility }\end{array}$ & S1 & Solyc03g. & c) & 0 & 0.02 & 0.415 & 0.00779 \\
\hline genes (down- & S2 & Solyc02g088210 & SPX domain-containing protein 4 & 0.457 & 0.000645 & 0.355 & $5.14 \mathrm{E}-09$ \\
\hline $\begin{array}{l}\text { regulated in nrd1 } \\
\text { mutants) }\end{array}$ & s3 & Solyc05g007440 & ARM repeat superfamily protein & 0.289 & $3.05 E-30$ & 0.348 & $4.42 \mathrm{E}-19$ \\
\hline
\end{tabular}



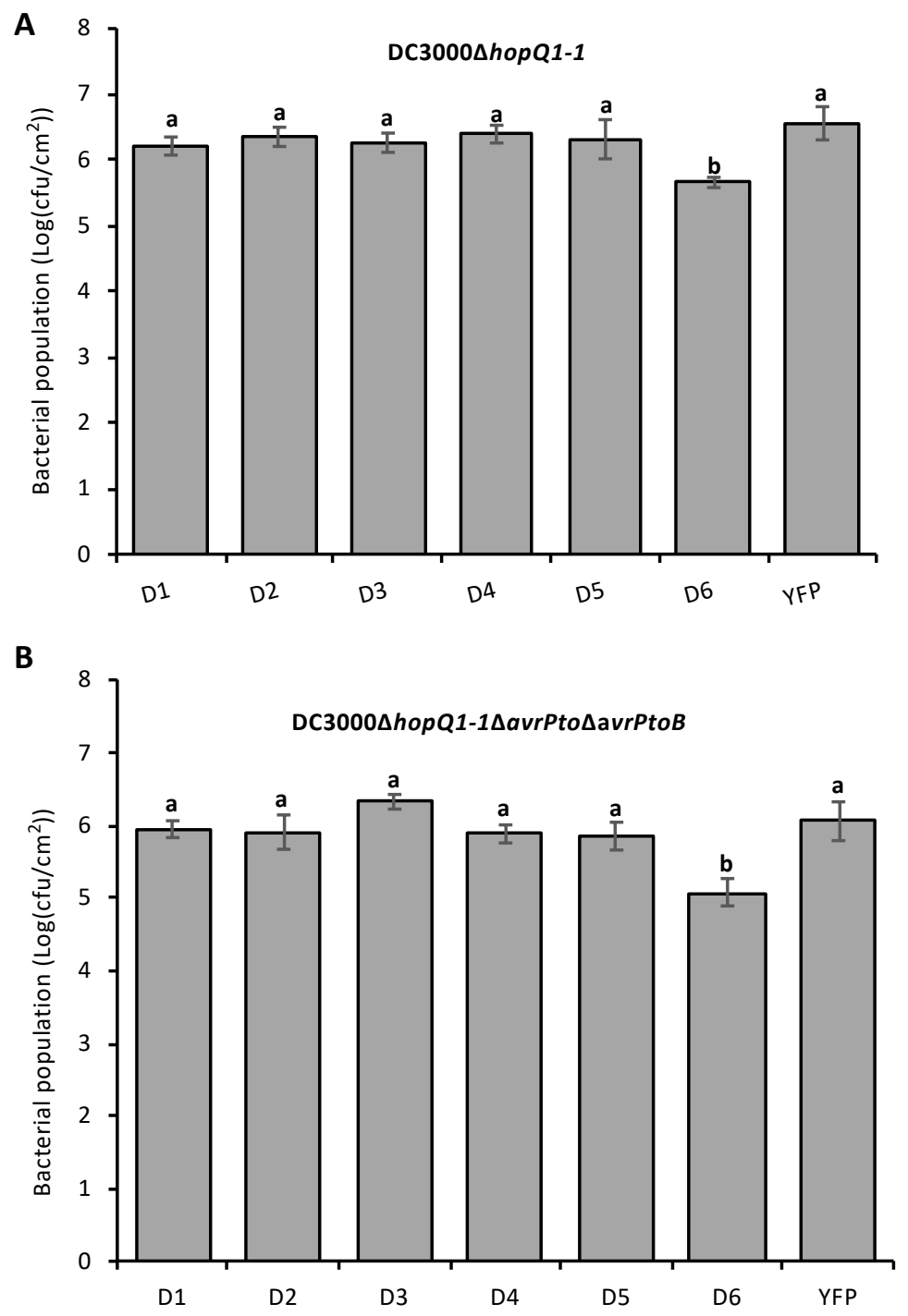

Figure 4. Testing putative defense-related genes in an agromonas assay. A-B, Leaves of fiveweek-old Nicotiana benthamiana plants were syringe-infiltrated with Agrobacterium (1D1249) strains $(O D=0.5)$ carrying a binary expression vector expressing each gene. Two days later, the same agroinfiltrated spots were syringe-infiltrated with $5 \times 10^{4} \mathrm{cfu} / \mathrm{mL}$ DC3000 $\Delta$ hopQ1-1 (A) or $5 \times 10^{4} \mathrm{cfu} / \mathrm{mL}$ DC3000 4 hopQ1-1 1 avrPto $\triangle a v r P t o B$ (B). Pst DC3000 populations were measured two days after the second infiltration. Bars show means \pm SD. Different letters indicate significant differences based on a one-way ANOVA followed by Student's $t$ test $(p<$ $0.05)$. ns, no significant difference. Three or four plants were tested with each gene in each experiment. Each experiment was performed at least two times with similar results. 
A MALSHPMTIFSLFLTFLALTAA^QSPMMAPTMPPSTMSMPPTTSTTTPPPMSSMSPPPS AMSPTPSTMSPPPMSPMTPSMSPMGPMTPTMSPMDSPPAPAGPGMAPGMSTPGPA PGPMGGESMASPPP*SSGFVHGISISMAMVAIIGSVALFF

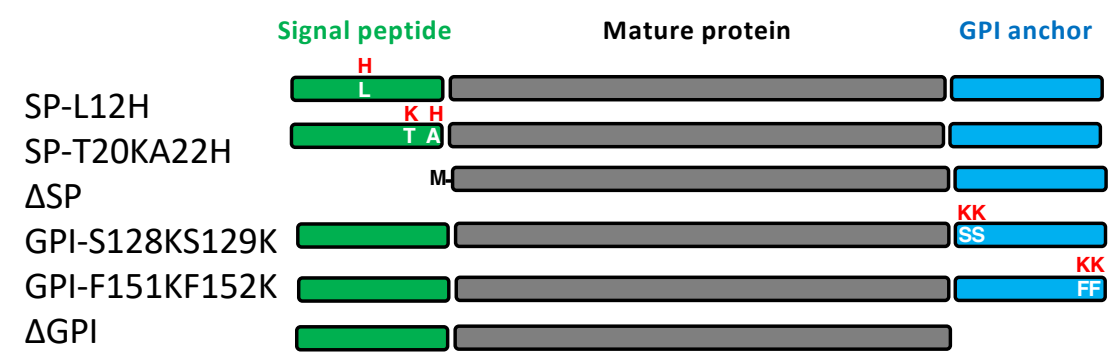

B

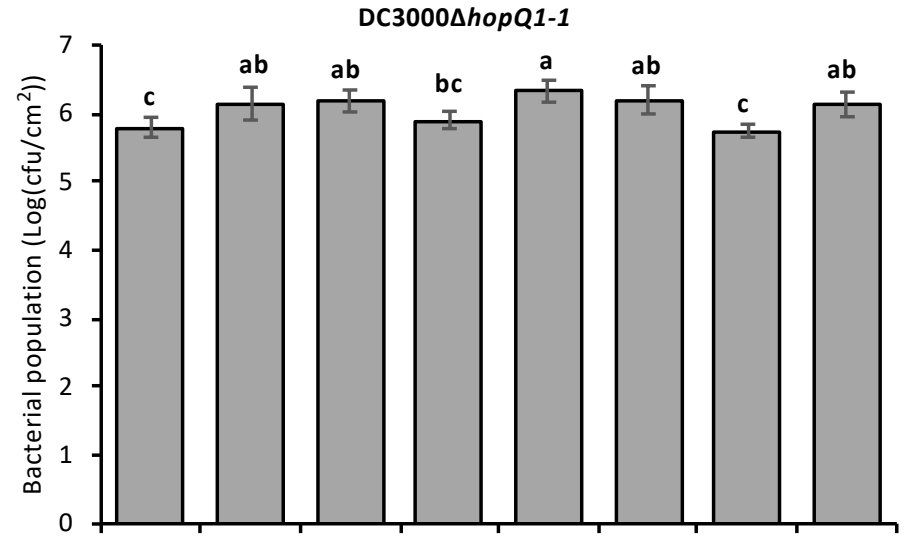

C

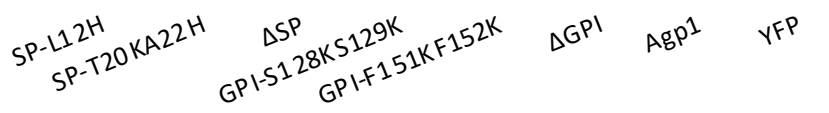

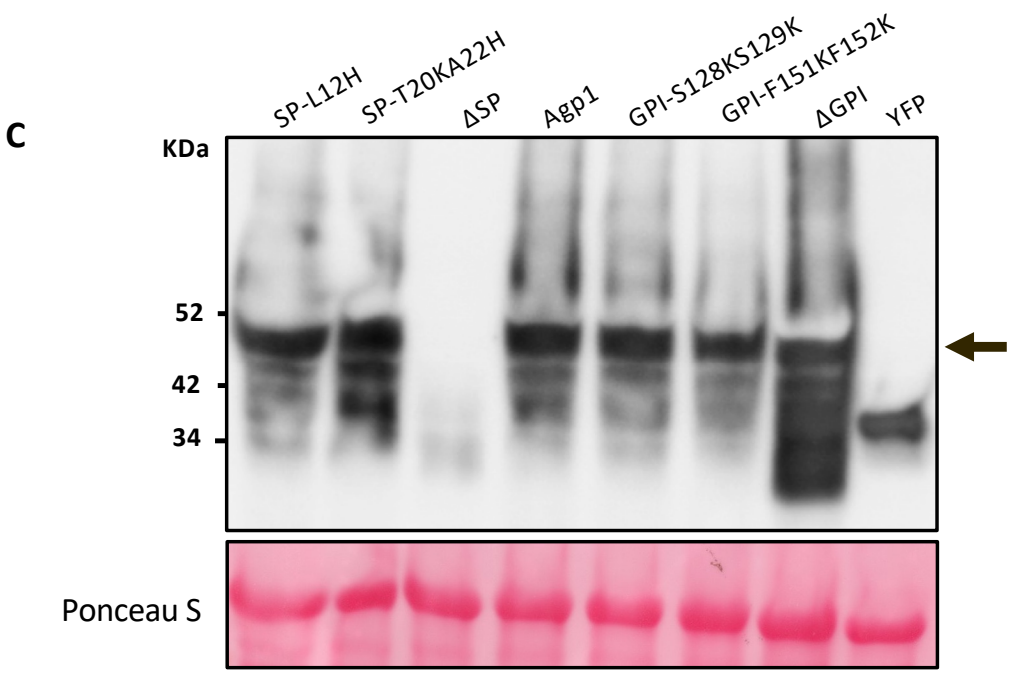

Figure 5. The signal peptide (SP) and glycosylphosphatidylinositol (GPI) anchor play a role in Agp1-mediated immunity to Pst. A, Top: amino acid sequence of the Agp1 protein. Signal peptide sequence is highlighted in green and the GPI-anchored sequence is highlighted in blue. Schematics show the substituted amino acids or deletions of the Agp1 protein, each fused to an HA epitope tag. B, Leaves of five-week-old $N$. benthamiana plants were syringeinfiltrated with Agrobacterium (1D1249) strains (OD $=0.5$ ) carrying a binary expression vector expressing each gene. Two days later, the same agroinfiltrated spots were syringe-infiltrated with $5 \times 10^{4} \mathrm{cfu} / \mathrm{mL}$ DC3000 4 hopQ1-1. Pst DC3000 populations were measured two days after the second infiltration. Bars show means \pm SD. Different letters indicate significant differences based on a one-way ANOVA followed by Student's $t$ test $(p<0.05)$. Three or four plants were tested with each gene in each experiment. The experiments were performed twice with similar results. C, Proteins were extracted from N. benthamiana leaves expressing each Agp1:HA variant two days after agroinfiltration. Proteins were detected by immunoblotting with an $\alpha-\mathrm{HA}$ antibody. 


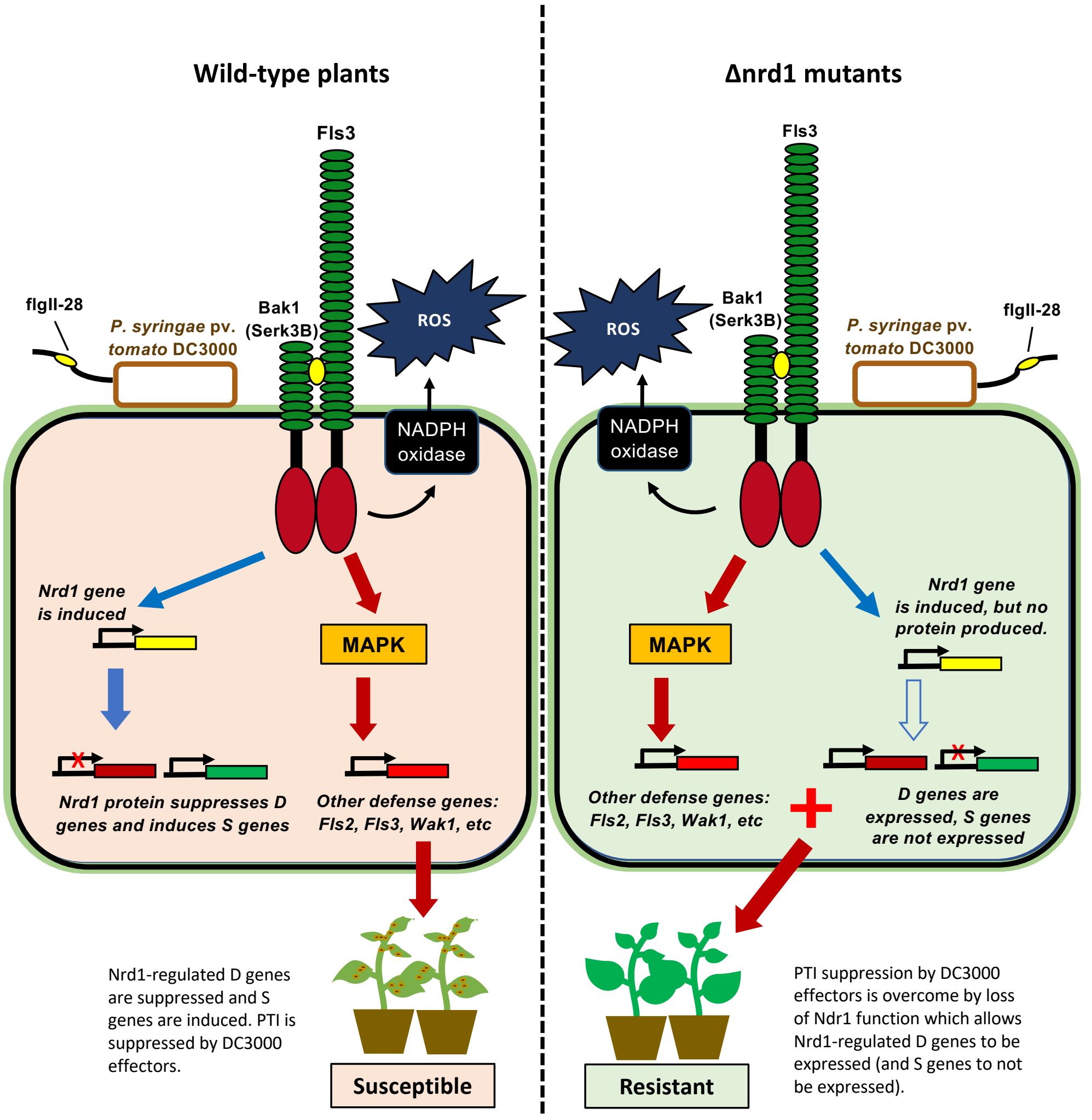

Figure 6. Proposed model for the enhanced resistance seen in $\Delta \mathrm{nrd} 1$ mutants. Fls3 appears to regulate two opposing host responses: 1) To resist Pst infection, Fls3 and other PRRs induce ROS, MAPK and other defense responses which inhibit Pst growth. 2) Fls3 also induces Nrd1 gene expression, and increases Nrd1 protein abundance, which suppresses a subset of defense genes and also induces a subset of susceptibility genes further promoting susceptibility to Pst infection. When Nrd1 is mutated, the subset of defense genes, including Agp1, are no longer suppressed (or are induced) and $\mathrm{S}$ genes are not expressed leading to enhanced resistance to Pst. 
Supplemental Information 
A Solyc03g114237 ITEMESSNINIVTASEKIERKTQEKIRRIQMKYLTSKLFSLIPPHH-HQSTKEVLTKQDK Solyc03g114233 MENNSVNNIVSTSSVQKLDRKTQEKNRRIQMKYLYAKLFSLIP----LNHSKEVLTQHDH Nrd1 -------MENTSPEKLDRKTQEKNRRIQMKYLSSKLFSLIPPHHHQYSAKDMVTQQDQ $::: *:: * * * * * * * * * * * * * *: * * * * * * * \quad::^{*}:::^{*}:: *$ :

Solyc03g114237 IDAAITYIKQLKERIEVLERRKEEVVAQETCDDSKKSMPTTTC-SIKSPMVEVKELDSTL Solyc03g114233 VDQATTF IEELKERVEVLKRRKDEVVAQI IGDDSKKS ISTTTC-TIK-----VRELDSTL Nrd1 IDQAITYIEKLKERVDVLMRRKDKIIAQGTSDDSKKFMPSTSCSNIKLPMIEVRELGSTI

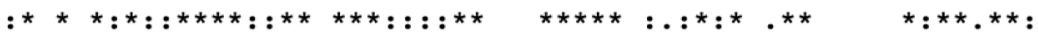

Solyc03g114237 EVILVSGLQKNFILQEVIKIIEQEGAQVVSANYSTIDDTIYYMIHAQVKIARLGIDASRV Solyc03g114233 EVILTSGLQKNFTLQEVIKIIEEEGAQVVTANYSTIDGTIYYTIHAOVKITRLGIDASRI Nrd1 EVILVSCLQKKFTMQEVIIILEEEGVQVVTANFSTIGDKVYYTIHAQVKITRLGVDASRV $* * * * . * * * *: *: * * * * *: *: * * . * * *: * *: * * * \ldots: \ldots * * * * * * * *: * * *: * * * *:$

Solyc03g114237 HLRLQKMVC Solyc03g114233 HFRLQKLVS

Nrd1 YLRLQNLIC

$:: * * *:::$.

B

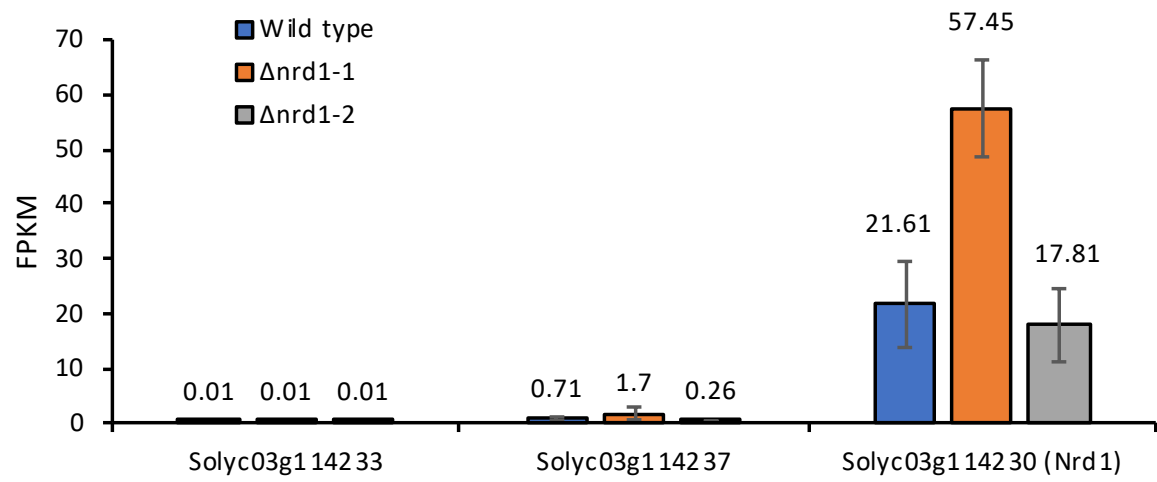

Supplemental Figure 1. The two closest Nrd1 homologs in tomato. A, Amino acid sequence alignment of the two closest tomato Nrd1 homologs. B, Transcript abundance of the two closest tomato $\mathrm{Nrd1}$ homologs in wildtype and $\Delta \mathrm{nrd} 1$ mutants, $6 \mathrm{~h}$ after treatment with $5 \times 10^{6} \mathrm{cfu} / \mathrm{mL}$ DC3000 $\Delta$ avrPto $\Delta a v r P t o B$ $(\mathrm{DC} 3000 \Delta \Delta)$. 
A

\begin{tabular}{ccc}
\hline Gene name & $\begin{array}{c}\text { Position of the } \\
\text { predicted element }\end{array}$ & $\begin{array}{c}\text { Predicted E- } \\
\text { box sequence }\end{array}$ \\
& +859 & CATTTG \\
& +216 & CATATG \\
& +108 & CAATTG \\
D1 & +56 & CACGTG \\
& +5 & CAACTG \\
\hline & +329 & CACTTG \\
\hline D2 & +875 & CAGCTG \\
& +805 & CACATG \\
D3 & +798 & CAATTG \\
& +63 & CATATG \\
\hline \multirow{2}{*}{ D4 } & +655 & CAAGTG \\
& +109 & CACGTG \\
\hline D5 & +73 & CACCTG \\
\hline \multirow{2}{*}{ D6 } & +850 & CATATG \\
& +499 & CAATTG \\
\hline \multirow{2}{*}{ S1 } & +889 & CATTTG \\
& +369 & CATATG \\
\hline & +910 & CAAATG \\
& +893 & CACTTG \\
& +875 & CAAATG \\
S2 & +489 & CAGTTG \\
& +39 & CATATG \\
\hline \multirow{2}{*}{ S3 } & +600 & CAAGTG \\
& +403 & CAAATG \\
& +219 & CATGTG \\
\hline & &
\end{tabular}

B

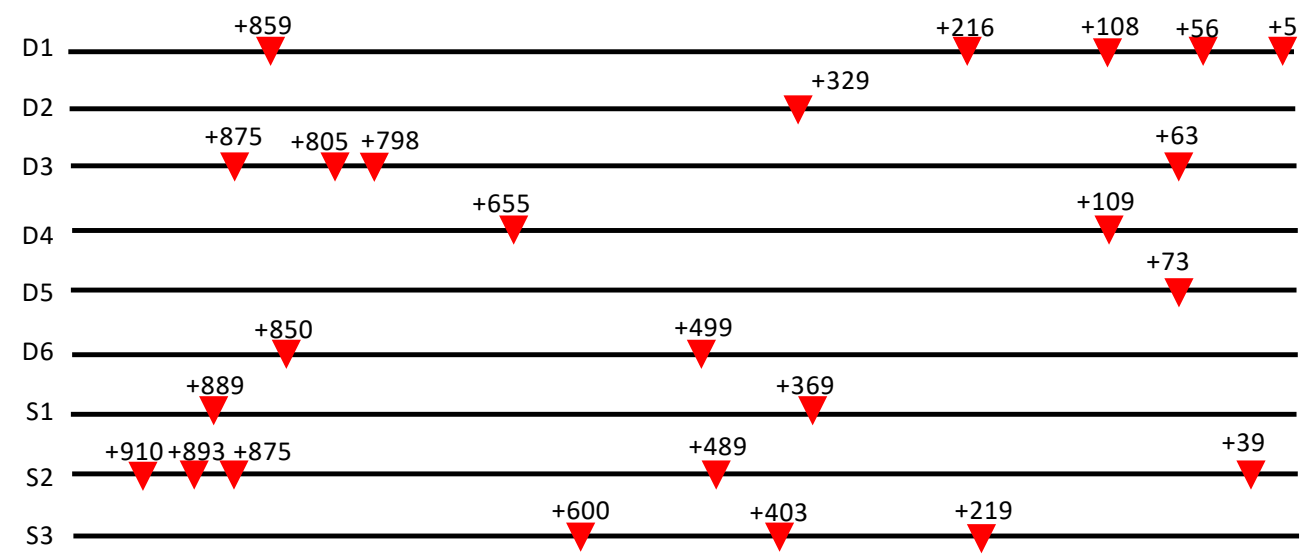

Supplemental Figure 2. Predicted E-box elements (CANNTG) in Nrd1-regulated putative defense and susceptibility genes. A-B, $1 \mathrm{~kb}$ DNA sequence upstream of the 5' untranslated region (5'UTR) or coding region (CDS) of each gene was analyzed by PlantPan2.0 (Chow et al., 2016) to identify potential bHLH-binding elements, denoted with inverted red triangles. The first nucleotide of the promoter sequence upstream of $5^{\prime}$ UTR or CDS is designated as " +1 ". 
A

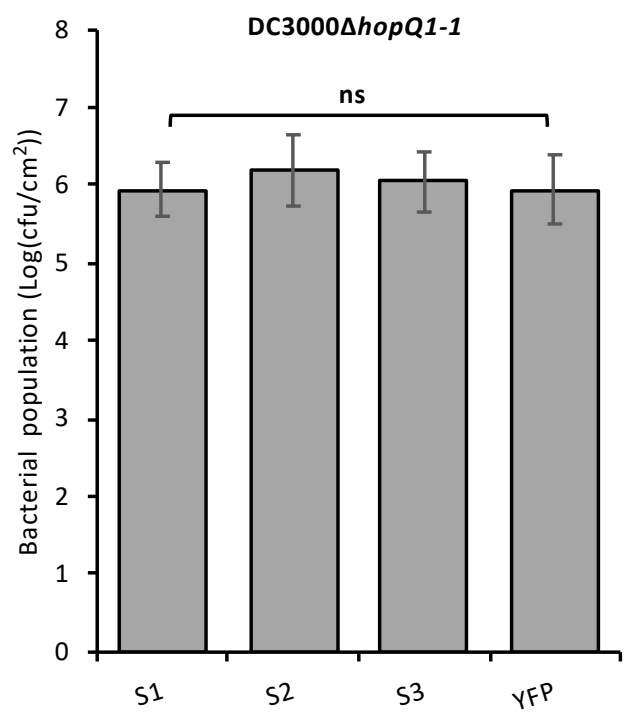

B

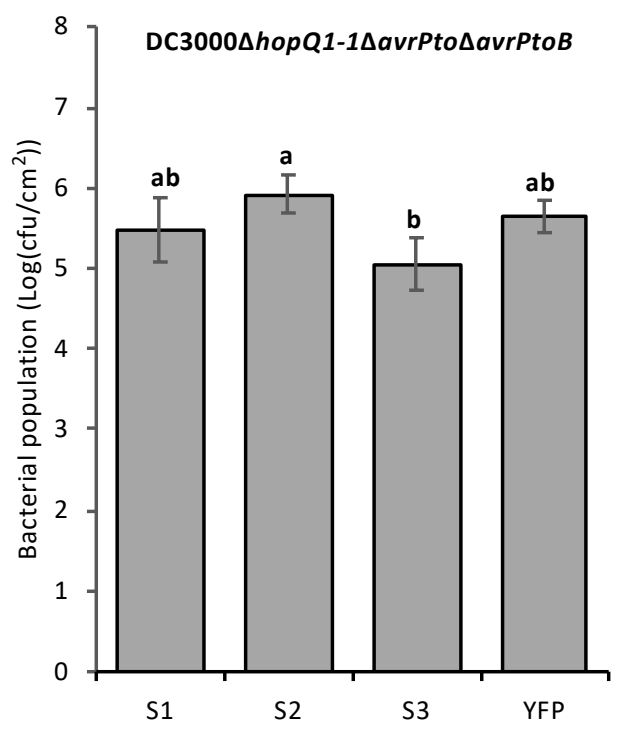

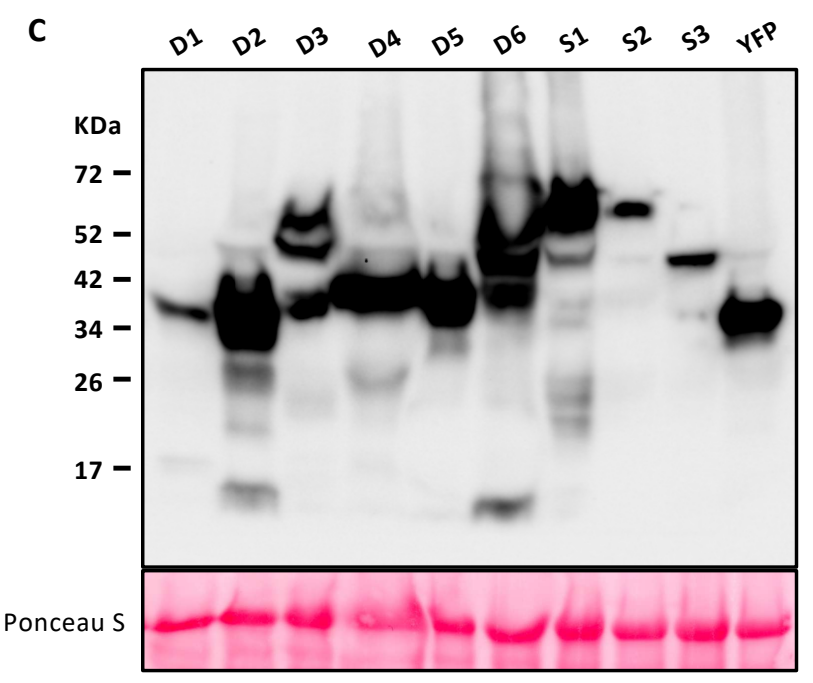

Supplemental Figure 3. Testing putative susceptibility genes in an agromonas assay and confirming expression of the D and S proteins. A-B, Five-week-old Nicotiana benthamiana plants were syringe-infiltrated with Agrobacterium strains (1D1249) containing a binary expression vector expressing each gene $(O D=0.5)$. Two days later, the same agro-infiltrated spots were syringeinfiltrated with $5 \times 10^{4} \mathrm{cfu} / \mathrm{mL}$ DC3000 4 hopQ1-1 (A) or $5 \times 10^{4} \mathrm{cfu} / \mathrm{mL} \mathrm{DC3000 \Delta hopQ1-}$ $1 \Delta a v r$ Pto $\triangle a v r P t o B(B)$. Bacterial populations were measured two days after infiltration. A-B, Bars represent means \pm SD. Different letters indicate significant differences based on a one-way ANOVA followed by Student's $t$ test $(p<0.05)$. ns, no significant difference. $\mathbf{C}$, Protein expression by western blotting. Proteins were extracted from $N$. benthamiana leaves two days after agroinfiltration. S proteins with an HA epitope tag were detected by immunoblotting with $\alpha-\mathrm{HA}$ antibody. 
Agp1 protein sequence:

MALSHPMTIFSLFLTFLALTAAQSPMMAPTMPPSTMSMPPTTSTTTPPPMSSM $\underline{S P P P S A M S P} \underline{\underline{S}} \underline{\mathrm{ST}} \underline{\mathrm{T}} \underline{\mathrm{S}} \underline{\mathrm{P}}$

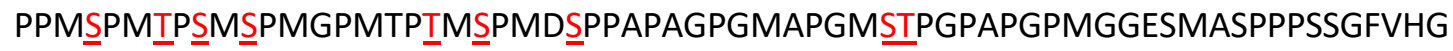
ISISMAMVAIIGSVALFF

\begin{tabular}{|c|c|c|}
\hline Position & Score & Comment \\
\hline 4 & 0.006 & \\
\hline 8 & 0.018 & \\
\hline 11 & 0.037 & \\
\hline 15 & 0.017 & \\
\hline 20 & 0.041 & \\
\hline 24 & 0.130 & \\
\hline 30 & 0.713 & Positive \\
\hline 34 & 0.767 & Positive \\
\hline 35 & 0.795 & Positive \\
\hline 37 & 0.887 & Positive \\
\hline 41 & 0.920 & Positive \\
\hline 42 & 0.768 & Positive \\
\hline 43 & 0.930 & Positive \\
\hline 44 & 0.885 & Positive \\
\hline 45 & 0.895 & Positive \\
\hline 46 & 0.882 & Positive \\
\hline 51 & 0.827 & Positive \\
\hline 52 & 0.890 & Positive \\
\hline 54 & 0.826 & Positive \\
\hline 58 & 0.872 & Positive \\
\hline 61 & 0.749 & Positive \\
\hline 63 & 0.652 & Positive \\
\hline 65 & 0.910 & Positive \\
\hline 66 & 0.776 & Positive \\
\hline 68 & 0.882 & Positive \\
\hline 73 & 0.628 & Positive \\
\hline 76 & 0.522 & Positive \\
\hline 78 & 0.874 & Positive \\
\hline 80 & 0.721 & Positive \\
\hline 86 & 0.465 & \\
\hline 88 & 0.680 & Positive \\
\hline 90 & 0.637 & Positive \\
\hline 94 & 0.738 & Positive \\
\hline 108 & 0.876 & Positive \\
\hline 109 & 0.710 & Positive \\
\hline 121 & 0.428 & \\
\hline 124 & 0.312 & \\
\hline 128 & 0.073 & \\
\hline 129 & 0.014 & \\
\hline 136 & 0.011 & \\
\hline 138 & 0.007 & \\
\hline 147 & 4.1E-06 & \\
\hline
\end{tabular}

Supplemental Figure 4. Prediction of glycosylation sites in the Agp1 protein. Glycosylation sites were predicted using NetOGlyc-4.0 (Steentoft et al., 2013) with a cutoff score higher than 0.5 (marked as "Positive"). The first amino acid of Agp1 protein is designated as position "1". Positive sites of glycosylated amino acids are highlighted in red and underlined. 
Supplemental Table 1 . Summary of disease assays with the $\Delta \mathrm{nrd} 1$ mutant plants.

\begin{tabular}{|c|c|c|c|}
\hline Bacterial strains & $\begin{array}{l}\text { Inoculum } \\
\text { (cfu/mL) }\end{array}$ & $\begin{array}{l}\text { Disease symptom } \\
\text { (compared to } \\
\text { wildtype) }\end{array}$ & $\begin{array}{l}\text { Bacterial growth } \\
\text { (compared to } \\
\text { wildtype) }\end{array}$ \\
\hline DC3000 & $5 \times 10^{6}$ & $n s^{1}$ & ns \\
\hline DC3000 $\Delta$ avrPto $\Delta$ avrPtoB & $5 \times 10^{4}$ & More resistant & Less bacterial growth \\
\hline NYS-T1 & $1 \times 10^{4}$ & ns & ns \\
\hline T1 & $2 \times 10^{4}$ & ns & ns \\
\hline Pst14 $\Delta$ avrPto & $2 \times 10^{4}$ & ns & ns \\
\hline Pst25 $\Delta$ avrPto & $2 \times 10^{4}$ & ns & ns \\
\hline Xanthomonas campestris pv. vesicatoria & $5 \times 10^{4}$ & ns & ns \\
\hline
\end{tabular}

${ }^{1}$ ns, no significant difference 
Supplemental Table 2. The $51 \mathrm{Nrd1}$-regulated putative defense and susceptibility genes identified by RNA-Seq.

\begin{tabular}{|c|c|c|c|c|c|c|c|}
\hline \multirow{2}{*}{ Gene ID } & \multicolumn{6}{|c|}{ RNA-Seq data from this study } & \multirow{2}{*}{ RNA-Seq data from Rosli et al. ${ }^{1}$} \\
\hline & $\begin{array}{l}\text { FPKM in } \\
\Delta \text { nrd1-1 } \\
\end{array}$ & $\begin{array}{l}\text { Dnrd1-1 } \\
\text { /wldtype }\end{array}$ & Adjusted P & $\begin{array}{l}\text { FPKM in } \\
\Delta \text { nrd1-2 } \\
\end{array}$ & $\begin{array}{c}\text { nrd1-2 } \\
\text { /wildtype } \\
\end{array}$ & Adjusted P & \\
\hline Solyc05g024190 (D1) & 3.7 & 2.8 & 0.0013 & 5.1 & 3.9 & 0.0079 & flgII-28 suppressed \\
\hline Solyc07g061790 (D2) & 216.42 & 4.4 & $2.45 E-05$ & 324.36 & 6.5 & $2.66 \mathrm{E}-08$ & $\begin{array}{c}\text { flgll-28 and csp22 suppressed/ } \\
\text { ETI suppressed }\end{array}$ \\
\hline Solyc02g077330 (D3) & 2.05 & 2.7 & 0.01 & 2.64 & 3.5 & 0.011 & $\begin{array}{l}\text { flgII-28/flg22/csp22 suppressed/ } \\
\text { ETI suppressed }\end{array}$ \\
\hline Solyc12g009650 (D4) & 1544.34 & 2.2 & $6.79 E-13$ & 1630.19 & 2.3 & 2.97E-05 & $\begin{array}{l}\text { flgII-28 and csp22 suppressed/ } \\
\text { ETI-suppressed }\end{array}$ \\
\hline Solyc11g019910 (D5) & 56.23 & 2.2 & 0.005 & 68 & 2.6 & 5.81E-05 & $\begin{array}{l}\text { flgll-28 and csp22 suppressed/ } \\
\text { ETI-induced }\end{array}$ \\
\hline Solyc08g078020 (D6) & 696.82 & 3.2 & $3.81 E-11$ & 800.1 & 3.6 & $3.40 \mathrm{E}-09$ & $\begin{array}{l}\text { flgll-28 and csp22 suppressed/ } \\
\text { ETI suppressed }\end{array}$ \\
\hline Solyc11g021060 & 917.98 & 4.4 & $1.01 \mathrm{E}-06$ & 985.23 & 4.7 & $2.45 \mathrm{E}-09$ & csp22 suppressed/ETI suppressed \\
\hline Solyc12g011010 & 2.29 & 3.0 & 0.033 & 3.1 & 4.0 & 0.0066 & ETI suppressed \\
\hline Solyc01g104720 & 502.78 & 2.2 & 0.0015 & 762.9 & 3.4 & $8.57 \mathrm{E}-12$ & csp22 suppressed/ETI suppressed \\
\hline Solyc03g019890 & 26.54 & 2.2 & $1.61 \mathrm{E}-14$ & 32 & 2.6 & $1.20 \mathrm{E}-18$ & csp22 suppressed/ETI suppressed \\
\hline Solyc06g160050 & 732.67 & 39.7 & $8.94 \mathrm{E}-10$ & 1134.4 & 61.5 & $3.29 \mathrm{E}-08$ & No record \\
\hline Solyc05g021245 & 16.12 & 2.6 & 0.004 & 97 & 15.8 & $1.57 \mathrm{E}-21$ & No record \\
\hline Solyc02g161340 & 10.46 & 5.0 & $4.87 \mathrm{E}-15$ & 10.62 & 5.1 & $6.12 \mathrm{E}-14$ & No record \\
\hline Solyc04g009850 & 17.36 & 4.0 & $1.23 \mathrm{E}-07$ & 12.97 & 3.0 & $4.40 \mathrm{E}-05$ & $\begin{array}{l}\text { flgll-28 and csp22 induced/ } \\
\text { ETI-induced }\end{array}$ \\
\hline Solyc12g017800 & 4.08 & 408.0 & $1.81 \mathrm{E}-32$ & 4.12 & 412.0 & $1.07 E-30$ & No expressed \\
\hline Solyc05g024230 & 7.65 & NA* & $1.80 \mathrm{E}-11$ & 9.74 & NA & $1.68 \mathrm{E}-13$ & Induced in hpBti9 and one hpPti line \\
\hline Solyc01g066790 & 103.32 & 430.5 & $6.94 \mathrm{E}-40$ & 42.82 & 178.4 & $1.20 \mathrm{E}-18$ & Induced in one hpPti line \\
\hline Solyc05g055460 & 1.38 & 46.0 & 0.0003 & 2.05 & 68.3 & 0.00015 & Not induced \\
\hline Solyc07g045127 & 0.64 & 64.0 & 0.0005 & 0.55 & 55.0 & 0.00073 & No record \\
\hline Solyc09g082340 & 0.51 & 51.0 & 0.0002 & 0.57 & 57.0 & 0.00099 & Not induced \\
\hline Solyc08g150133 & 0.13 & 13.0 & 0.016 & 0.24 & 24.0 & 0.00292 & No record \\
\hline Solyc07g026710 & 4.67 & 9.7 & 0.005 & 10.61 & 22.1 & $1.05 \mathrm{E}-13$ & Not induced \\
\hline Solyc03g096430 & 23.19 & 105.4 & $3.31 \mathrm{E}-12$ & 4.99 & 22.7 & $5.85 \mathrm{E}-08$ & Not induced \\
\hline Solyc12g036740 & 1.44 & 12.0 & 0.022 & 2.62 & 21.8 & 0.00418 & Not induced \\
\hline Solyc07g055490 & 0.56 & 18.7 & $8.11 \mathrm{E}-06$ & 0.45 & 15.0 & 0.00468 & Not induced \\
\hline Solyc12g087830 & 25.9 & 4.6 & 0.024 & 70.28 & 12.5 & $7.02 \mathrm{E}-23$ & Not clear \\
\hline Solyc07g056704 & 0.54 & 6.8 & 0.0002 & 1.01 & 12.6 & $2.50 \mathrm{E}-08$ & No record \\
\hline Solyc03g121900 & 11.03 & 6.9 & $5.33 \mathrm{E}-12$ & 18.23 & 11.5 & $6.67 \mathrm{E}-16$ & Induced in one hpPti line \\
\hline
\end{tabular}

${ }^{1}$ Rosli et al., (2013). Genome Biology 14:R139

${ }^{2}$ Shown in bold are the genes selected for further functional characterization based on criteria discussed in the Results. 
Supplemental Table 2 (continued). The $51 \mathrm{Nrd1}$-regulated putative defense and susceptibility genes identified by RNA-Seq.

\begin{tabular}{|c|c|c|c|c|c|c|c|}
\hline \multirow[b]{2}{*}{ Gene ID } & \multicolumn{6}{|c|}{ RNA-seq in this study } & \multirow{2}{*}{ Rosli's RNA-seq data } \\
\hline & $\begin{array}{l}\text { FPKM in } \\
\text { Anrd1-1 }\end{array}$ & $\begin{array}{l}\text { Dnrd1-1 } \\
\text { /wildtype }\end{array}$ & Adjusted P & $\begin{array}{l}\text { FPKM in } \\
\Delta \text { nrd1-2 }\end{array}$ & $\begin{array}{l}\Delta \text { nrd1-2 } \\
\text { /wildtype }\end{array}$ & $\begin{array}{l}\text { Adjusted } \\
\text { P }\end{array}$ & \\
\hline Solyc12g062200 & 18.92 & 7.2 & 0.0095 & 27.17 & 10.4 & 0.0004 & Not clear \\
\hline Solyc03g096420 & 4.19 & 17.5 & 5.19E-05 & 2.14 & 8.9 & 0.0015 & Not induced \\
\hline Solyc07g056708 & 0.31 & 7.8 & 0.037 & 0.36 & 9.0 & 0.0161 & No record \\
\hline Solyc00g011660 & 0.48 & 4.4 & 0.004 & 0.85 & 7.7 & $7.83 \mathrm{E}-05$ & Not induced \\
\hline Solyc05g051310 & 1.23 & 12.3 & $3.12 \mathrm{E}-05$ & 0.72 & 7.2 & 0.0421 & Not induced \\
\hline Solyc08g067530 & 1.82 & 4.8 & 0.0023 & 2.31 & 6.1 & 0.0005 & Not clear \\
\hline Solyc09g089780 & 22.22 & 10.7 & $3.47 E-06$ & 12.96 & 6.2 & 0.0015 & $\operatorname{csp} 22$ and flg22 induced \\
\hline Solyc01g079920 & 0.53 & 8.8 & $1.57 \mathrm{E}-05$ & 0.34 & 5.7 & 0.0043 & csp22 and flg22/flgII-28 induced \\
\hline Solyc01g107370 & 4.36 & 5.5 & 4.09E-06 & 3.9 & 4.9 & $1.75 \mathrm{E}-05$ & Not induced \\
\hline Solyc07g055690 & 337.65 & 12.2 & $7.22 \mathrm{E}-09$ & 133.88 & 4.8 & 0.0059 & $\begin{array}{c}\text { csp22 and flg22/flgll-28 induced/ } \\
\text { ETI induced? }\end{array}$ \\
\hline Solyc10g084600 & 9.14 & 3.9 & 0.009 & 7.95 & 3.4 & 0.0147 & ETI suppressed? \\
\hline Solyc07g009380 & 397.73 & 3.9 & $2.02 \mathrm{E}-11$ & 319.41 & 3.1 & $4.35 \mathrm{E}-07$ & Not clear \\
\hline Solyc09g091060 & 3.39 & 4.5 & $3.92 \mathrm{E}-05$ & 2.01 & 2.7 & 0.0008 & Not induced \\
\hline Solyc12g011200 & 6.75 & 10.7 & $2.01 \mathrm{E}-08$ & 1.68 & 2.7 & 0.034 & Not induced \\
\hline Solyc02g065470 & 346.18 & 3.4 & $5.52 \mathrm{E}-09$ & 249.33 & 2.4 & 0.0091 & ETI induced \\
\hline $\begin{array}{l}\text { Solyc03g112030 } \\
\text { (S1) }\end{array}$ & 1.74 & 0.31 & 0.0238 & 2.31 & 0.41 & 0.0078 & flgll-28 induced/ETI induced \\
\hline $\begin{array}{l}\text { Solyc02g088210 } \\
\text { (S2) }\end{array}$ & 5.29 & 0.46 & 0.0006 & 4.11 & 0.36 & 5.14E-09 & csp22 induced/ETI induced \\
\hline $\begin{array}{l}\text { Solyc05g007440 } \\
\text { (S3) }\end{array}$ & 7.36 & 0.29 & $3.05 E-30$ & 8.87 & 0.35 & 4.42E-19 & ETI suppressed \\
\hline Solyc08g074710 & 0.07 & 0.03 & 0.0021 & 0.46 & 0.20 & 0.0164 & No expressed \\
\hline Solyc02g030520 & 0.11 & 0.03 & 0.0067 & 0.24 & 0.06 & 0.0432 & No expressed \\
\hline Solyc07g064370 & 0.02 & 0.02 & 0.0001 & 0.03 & 0.02 & 0.0322 & Not induced \\
\hline Solyc07g064380 & 0.03 & 0.02 & 0.0009 & 0.01 & 0.01 & 0.0014 & Not induced \\
\hline Solyc06g043150 & 0.23 & 0.21 & 0.0037 & 0.48 & 0.44 & 0.0354 & Not induced \\
\hline
\end{tabular}


Supplemental Table 3. RNA-Seq data showing the transcript abundance of selected immunity-associated genes in $\triangle$ nrd1 mutants when inoculated with DC3000 $\Delta$ avrPto $\Delta a v r P t o B$.

\begin{tabular}{|c|c|c|c|c|c|c|c|c|c|}
\hline \multirow{2}{*}{$\begin{array}{l}\text { Gene } \\
\text { name }\end{array}$} & \multirow{2}{*}{ Gene ID } & \multicolumn{2}{|c|}{ FPKM } & \multirow{2}{*}{$\begin{array}{l}\text { Anrd1-1 } \\
\text { /wildtype }\end{array}$} & \multirow{2}{*}{ Adjusted P } & \multicolumn{2}{|c|}{ FPKM } & \multirow{2}{*}{$\begin{array}{l}\text { Dnrd1-2 } \\
\text { /wildtype }\end{array}$} & \multirow{2}{*}{ Adjusted $\mathrm{P}$} \\
\hline & & $\Delta n r d 1-1$ & Wildtype & & & $\Delta \mathrm{nrd1-2}$ & Wildtype & & \\
\hline Wak1 & Solyc09g014720 & 15.32 & 10.61 & 1.44 & 0.45 & 8.1 & 10.61 & 0.76 & 0.75 \\
\hline Fls2.1 & Solyc02g070890 & 4.63 & 3.03 & 1.53 & 0.03 & 3.37 & 3.03 & 1.11 & 0.74 \\
\hline Fls3 & Solyc04g009640 & 16.93 & 10.98 & 1.54 & 0.37 & 7.66 & 10.98 & 0.70 & 0.46 \\
\hline Bti9 & Solyc07g049180 & 31.78 & 33.9 & 0.94 & 0.99 & 26.18 & 33.9 & 0.77 & 0.01 \\
\hline Core & Solyc03g096190 & 2.05 & 1.3 & 1.58 & 0.52 & 0.81 & 1.3 & 0.62 & 0.27 \\
\hline
\end{tabular}


Supplemental Table 4. Primers used in this study.

\begin{tabular}{|c|c|c|c|}
\hline Primer name & Primer sequence & Purpose & Solyc ID \\
\hline \multirow{2}{*}{ S1_CDS } & F:TTCGAATTCCAAGCTTGCCCATGATTTCCTTATTTGCGGTATTTCC & \multirow{2}{*}{$\begin{array}{l}\text { To clone the coding region of } \\
\text { S1 into pJLSmart }\end{array}$} & \multirow{2}{*}{ Solyc03g112030 } \\
\hline & R:ATAGGAATTCGGATCCGCCCGAATGCGTGGAGTTGCAACGAC & & \\
\hline \multirow{2}{*}{ S2_CDS } & F:TTCGAATTCCAAGCTTGCCCATGAAATTCGGTAAAGAGTTCACAAC & \multirow{2}{*}{$\begin{array}{l}\text { To clone the coding region of } \\
\text { S2 into pJLSmart }\end{array}$} & \multirow{2}{*}{ Solyc02g088210 } \\
\hline & R:ATAGGAATTCGGATCCGCCCGTTCCGGTGGATGGAAATCCTC & & \\
\hline \multirow{2}{*}{ S3_CDS } & F:TTCGAATTCCAAGCTTGCCCATGGCGACGGAGCTAGAAGAATTG & \multirow{2}{*}{$\begin{array}{l}\text { To clone the coding region of } \\
\text { S3 into pJLSmart }\end{array}$} & \multirow{2}{*}{ Solyc05g007440 } \\
\hline & R:ATAGGAATTCGGATCCGCCCGCGAAGATGTCTCTGCTAACGAAG & & \\
\hline \multirow{2}{*}{ D1_CDS } & F:TTCGAATTCCAAGCTTGCCCATGTCAATATGGGGAAAAATGTTCTTTC & \multirow{2}{*}{$\begin{array}{l}\text { To clone the coding region of } \\
\text { D1 into pJLSmart }\end{array}$} & \multirow{2}{*}{ Solyc05g024190 } \\
\hline & R:ATAGGAATTCGGATCCGCCCGACTCCTATCTTCACCAGTTACCG & & \\
\hline \multirow{2}{*}{ D2_CDS } & F:TTCGAATTCCAAGCTTGCCCATGCTTAGTGTAAGTATGAATCTGTTG & \multirow{2}{*}{$\begin{array}{l}\text { To clone the coding region of } \\
\text { D2 into pJLSmart }\end{array}$} & \multirow{2}{*}{ Solyc07g061790 } \\
\hline & R:ATAGGAATTCGGATCCGCCCGAATGGCAAGTGCTTTTTTCCAAATCA & & \\
\hline \multirow{2}{*}{ D3_CDS } & F:TTCGAATTCCAAGCTTGCCCATGCTGATGAGGCTTCTGATTATC & \multirow{2}{*}{$\begin{array}{l}\text { To clone the coding region of } \\
\text { D3 into pJLSmart }\end{array}$} & \multirow{2}{*}{ Solyc02g077330 } \\
\hline & R:ATAGGAATTCGGATCCGCCCGGTCTAGTAAATCAACATTAATAGCTTTAAG & & \\
\hline \multirow{2}{*}{ D4_CDS } & F:TTCGAATTCCAAGCTTGCCCATGGAGTTCTCTAAGATAACTTCACTTC & \multirow{2}{*}{$\begin{array}{l}\text { To clone the coding region of } \\
\text { D4 into pJLSmart }\end{array}$} & \multirow{2}{*}{ Solyc12g009650 } \\
\hline & R:ATAGGAATTCGGATCCGCCCGAATTTCAGATTGGAAACAAGTGTAGCC & & \\
\hline \multirow{2}{*}{ D5_CDS } & F:TTCGAATTCCAAGCTTGCCCATGGAAAATTATAGTCCTTATAATTCCAA & \multirow{2}{*}{$\begin{array}{l}\text { To clone the coding region of } \\
\text { D5 into pJLSmart }\end{array}$} & \multirow{2}{*}{ Solyc11g019910 } \\
\hline & R:ATAGGAATTCGGATCCGCCCGATAAAGGTGATTTATGAAAGCTAAAGCA & & \\
\hline \multirow{2}{*}{ D6_CDS } & F:TTCGAATTCCAAGCTTGCCCATGGCTCTCTCACATCCTATGAC & \multirow{2}{*}{$\begin{array}{l}\text { To clone the coding region of } \\
\text { D6 into pJLSmart }\end{array}$} & \multirow{2}{*}{ Solyc08g078020 } \\
\hline & R:ATAGGAATTCGGATCCGCCCGGAAAAAAAGTGCTACACTTCCAATAATTG & & \\
\hline \multirow{2}{*}{ Agp1-SP-L12H } & F:ATTTTCTCTCATTTTCTTACATTTTTAGC & \multirow{2}{*}{$\begin{array}{l}\text { For mutagenesis in the signal } \\
\text { peptide sequence of Agp1 }\end{array}$} & \multirow{2}{*}{ Solyc08g078020 } \\
\hline & R:TGTCATAGGATGTGAGAG & & \\
\hline \multirow{2}{*}{$\begin{array}{l}\text { Agp1-SP- } \\
\text { T2OKA22H }\end{array}$} & F:TCACCAATCCCCCATGATGGC & \multirow{2}{*}{$\begin{array}{l}\text { For mutagenesis in the signal } \\
\text { peptide sequence of Agp1 }\end{array}$} & \\
\hline & R:GCCTTGAGGGCTAAAAATGTAAGAAAAAG & & solycurgu \\
\hline Agp1-GPI- & F:TCCACCTCCAAAGAAGGGATTTGTTCATGGAATTAG & For mutagenesis in the GPI & Solvcos \\
\hline S128KS129K & R:GAAGCCATTGACTCACCAC & anchor sequence of Agp1 & 501 \\
\hline Agp1-GPI- & F:TGTAGCACTTAAGAAGCGGGCGGATC & For mutagenesis in the GPI & 8020 \\
\hline F151KF152K & R:CTTCCAATAATTGCTACC & anchor sequence of Agp1 & U8gu/ $/ 80<0$ \\
\hline & F:TTCGAATTCCAAGCTTGCCCATGCAATCCCCCATGATGGCCCCA & To delete the signal peptide & \\
\hline & ATAGGAATTCGGATCCGCCCGGAAAAAAAGTGCTACACTTCCAATAATTG & & \\
\hline & R:TTCGAATTCCAAGCTTGCCCATGGCTCTCTCACATCCTATGAC & To delete the GPI anchor & \\
\hline $1-\Delta \mathrm{OTI}$ & ATAGGAATTCGGATCCGCCCGTGGAGGTGGAGAAGCCATTGAC & sequence of Agp1 & $0<0$ \\
\hline
\end{tabular}

